\title{
THE TIME TO OFFER TREATMENTS FOR COVID-19
}

Binh T. Ngo, M.D.1,2,*

Binh.Ngo@med.usc.edu

Paul Marik, M.D., F.C.C.P., F.C.C.M.

Eastern Virginia Medical School|

Department of Internal Medicine|

Chief, Pulmonary and Critical Care Medicine|

825 Fairfax Ave, Rm 575, Norfolk, VA 23507|

marikpe@evms.edu

Pierre Kory, M.D., M.P.A

Pulmonary and Critical Care Medicine

Aurora St. Luke's Medical Center

Milwaukee, Wisconsin .

pierrekory@icloud.com

Leland Shapiro, M.D.

Rocky Mountain Regional Veterans Affairs Medical Center in Aurora, CO and University of Colorado Anschutz Medical Campus in Aurora, CO

Supported by The Emily Foundation in Boston, MA

lelandshapiro@cuanschutz.edu 
Raphael Thomadsen, P.h.D.

Washington University in St. Louis

thomadsen@wustl.edu

Jose Iglesias, D.O., F.A.S.N.

Jersey Shore University Medical Center, Neptune NJ, Hackensack Meridian School of Medicine at Seton Hall

Jiglesias23@gmail.com

Stephen Ditmore, B.A.

Parkchester Times

stephen.ditmore@gmail.com

Marc Rendell, M.D.2,*

The Rose Salter Medical Research Foundation

Newport Coast, CA 92657

rendell@asndi.com

Joseph Varon, M.D., FACP, FCCP, FCCM, FRSM

United Memorial Medical Center 
University of Texas School of Medicine

Houston, Texas, USA

joevaron@roamer.net

Michael Dubé, M.D.1

mdube@med.usc.edu

Neha Nanda, M.D.1

Neha.nanda@med.usc.edu

Gino In, M.D., M.P.H.1

Gino.In@med.usc.edu

Daniel Arkfeld,M.D. 1

arkfeld@med.usc.edu

Preet Chaudhary, M.D.1

Preet.chaudhary@med.usc.edu

Vito M. Campese, M.D. 1

campese@med.usc.edu

Diana L. Hanna, M.D. 1

Diana.Hanna@med.usc.edu 
David E. Sawcer, M.D. Ph.D.1
David.sawcer@med.usc.edu

Glenn Ehresmann, M.D.1

Glenn.ehresmann@med.usc.edu

David Peng, M.D., M.P.H.1

David.Peng@med.usc.edu

Miroslaw Smogorewski, M.D.1

smogorze@med.usc.edu

April Armstrong, M.D., M.P.H.1

April.armstrong@med.usc.edu

Rajkumar Dasgupta, M.D.1

"Dasgupta, Rajkumar" <rdasgupt@ med.usc.edu>

Fred Sattler, M.D.1

fsattler@usc.edu

Denise Brennan-Rieder P.h.D.

CoronaTracker Community Research Group

dbrennanrieder@gmail.com 
Cristina Mussini, M.D.

University of Modena and Reggio Emilia in Italy

Cristina.mussini@unimore.it

Oriol Mitja, Ph.D.

Hospital Universitari Germans Trias i Pujol

Badalona, Spain

omitja@flsida.org

Vicente Soriano, M.D. Ph.D.

UNIR Health Sciences School \& Medical Center

C/ Almansa 101

Madrid 28040, Spain

Vicente.soriano@unir.net

Nicolas Peschanski, M.D., Ph.D

UniversityHospital of Rennes

Rennes, France

nicolas.peschanski@chu-rennes.fr

Gilles Hayem, M.D.

Hôpital Paris Saint-. Joseph, 75014

Paris, France.

ghayem@ghpsj.fr

Marco Confalonieri, M.D. 
Azienda Ospedaliero-Universitaria di Trieste

Trieste, Italia

marco.confalonieri@asugi.sanita.fvg.it

Maria Carmela Piccirillo, M.D.

Istituto Nazionale Tumori, IRCCS, Fondazione G. Pascale

Napoli, Italia

m.piccirillo@istitutotumori.na.it

Antonio Lobo-Ferreira, M.D., Ph.D.

Unidade de Investigação Cardiovascular (UniC), Faculdade de Medicina da Universidade do Porto, Centro Hospitalar Universitário de São João, Porto, and Hospital Rainha Santa Isabel, Marco de Canaveses, Portugal Aloboferreira@gmail.com

Iraldo Bello Rivero M.Sc., Ph.D.

Department of Clinical Investigations

Center for Genetic Engineering and Biotechnology, Ave 31 e/ 158 and 190. Cubanacan, Playa, 10600

Havana, Cuba.

iraldo.bello@cigb.edu.cu

Eivind H. Vinjevoll, M.D.

Volda Hospital HMR, Norway. 
Eivind.vinjevoll@gmail.com

Daniel Griffin, M.D., Ph.D.*,3

ProHEALTH, an OPTUM Company

Columbia University

College of Physicians and Surgeons

Email: danielgriffinmd@gmail.com

Ivan FN Hung, MBChB, M.D., MRCP, FRCP.*,3

Li Ka Shing Faculty of Medicine

University of Hong Kong

Ivanhung@hku.hk

1 From the Keck Medical School of USC

2 From the Rose Salter Medical Research Foundation

3 CoSenior author

* Corresponding author 
BACKGROUND As of January 1, 2021, there have been 81,947,503 confirmed cases of COVID19 , resulting in 1,808,041 deaths worldwide. Several vaccines are now available for emergency use, but it will take many months to immunize the world's population. There is a pressing need for outpatient treatment now. We reviewed the possible options

METHODS We reviewed up-to-date information from several sources to identify potential treatments to be utilized now for COVID-19. We searched for all ongoing, completed and published trial results with subject numbers of 100 or more, and used a targeted search to find announcements of unpublished trial results.

\section{RESULTS}

As of December 27, 2020, we identified 750 trials currently in recruitment phase. Of these, 122 were directed at prevention in healthy individuals, 100 were classified as treatment of outpatients with documented infection, and 390 were for treatment of hospitalized inpatients. There were 9 trials focusing on the post discharge Tail phase. Among the trials, there were 60 vaccine trials, 120 trials of hydroxychloroquine, 33 trials of alternative therapy, 12 trials of colchicine, 38 trials of anticoagulants, 22 trials of the RNA polymerase inhibitor favipiravir (FVP), 19 trials of interferons, 18 trials of glucocorticoid, and 58 trials of plasma based products. Closure of enrollment was projected by the end of the year for 153 trials. We found 83 publications reporting findings in human studies on 14 classes of agents, and on 7 vaccines. There were 45 randomized or active controlled studies, the rest retrospective observational analyses. Most publications dealt with hospitalized patients, only 18 publications in outpatients. Remdesivir, convalescent plasma, and synthetic anti-spike protein antibodies have been granted emergency use authorization in the United States. There is also support for glucocorticoid treatment of the COVID-19 respiratory distress 
syndrome. There is data supporting the use of several antiviral medications, some of which are in use in other countries.

CONCLUSION. Vaccines and antibodies are highly antigen specific. There is a need for antiviral agents in addition to mass immunization. It will be necessary for public health authorities to make hard decisions, with limited data, to prevent the continued spread of the disease and deaths. 


\section{INTRODUCTION}

SARS-Cov-2 spread with extraordinary speed from its origin in December 2019 in Wuhan, China. As of January 1, 2021, there have been 81,947,503 confirmed cases of COVID-19, resulting in 1,808,041 deaths worldwide affecting 220 countries and territories (1). Symptomatic COVID-19 exhibits a characteristic sequence of phases related to the primary viral attack, manifesting as an influenza-like illness, affecting $80 \%$ of infected individuals. Then, in patients destined for severe disease, within seven to 10 days of onset of symptoms, an organizing pneumonia develops which requires assisted mechanical ventilation in up to $5 \%$ of patients (See Figure 1) (2,3). Elevated cytokines and a coagulopathy at this pulmonary stage suggests an immune reaction as probable cause $(4,5)$.

In mainland China, vigorous efforts to contain the spread of COVID-19 by home isolation, closure of business activity, travel bans, and tracking and control of contacts succeeded. As of December 10, China has had 96,762 confirmed cases and 4,789 deaths, but the number of new cases has been low since April (1). Similar measures contained the epidemic in Taiwan and in New Zealand (1). However, the disease has not been controlled in the rest of the World, particularly Europe where there have been 26,490,355 cases with 582,016 deaths and the United States (USA) where, despite only a fifth of the population of China, there have been 19,746,390 confirmed cases of COVID-19 and 335,789 deaths. (1). In the Western World, as in China, the response to the pandemic was through reduction of person-to-person contact. Beginning in early March, social gatherings and meetings ended; schools and businesses were closed along with recreation areas, parks, and beaches. These social distancing efforts blunted the spread of the 
disease, but not with the results achieved in China. Due to economic pressures, epidemiologic containment was relaxed resulting in a significant ongoing surge well surpassing the original April peak.

The major industrialized countries have made an unprecedented effort to rapidly develop vaccines for COVID-19. Two mRNA vaccines have demonstrated $90 \%$ effectiveness at two months post immunization, and mass vaccination has begun. However, in view of the continuing daily increase in new cases and deaths, we believe that it is unwise to place sole reliance on immunization alone. Our goal was to assess the options at the present time for release of pharmacologic agents to treat and to prevent COVID-19 while pursuing widespread vaccination in 2021.

\section{METHODS}

2.1 CLINICAL TRIALS: We reviewed up-to-date information from multiple sources to identify potential treatments for COVID-19: The ReaganUdall Expanded Access Navigator COVID-19 Treatment Hub was used to track the efforts of companies to develop therapeutic interventions. We searched for investigational trials in active recruitment and those that have completed enrollment. We used (A) covid-trials.org, a registry to collate all trials in real time with data pulled from the International Clinical Trials Registry Platform and all major national registries (6). We cross validated information on (B) clinicaltrials.gov, the registry of clinical trials information maintained by the United States National Library of Medicine. We further cross referenced the trials on C) the World Health Organization's International Clinical Trials Registry Platform (WHO ICTRP), and (D) (Cochrane COVID-19 Study Register. We excluded studies which were clearly observational with multiple different treatments, with no means of 
comparison. We further set a cutoff of 100 for numbers of subjects since smaller trial size typically lacks statistical power to enable regulatory approval. For each trial selected, we documented the setting of patient contact, either hospital or outpatient, the type of control procedure, the date the trial was initially registered, and the proposed date of completion of enrollment.

2.2 PUBLISHED TRIAL RESULTS: Our search was carried on the week of December 27, 2020. We identified all publications on pubmed.gov to find peer reviewed articles, on medRxiv to find preprint reports and the WHO Global Literature on Coronavirus Disease. We further carried out daily Google ${ }^{\mathrm{TM}}$ searches on each potential treatment to find preliminary reports, typically presented as press releases, reviewed by a journalist. We included all publications in our results as well as trial results posted as complete on Clinicaltrials.gov. We did not exclude trials with less than 100 subjects, since many reports were interim, with trials ongoing.

2.3 VIRTUAL DISCUSSIONS AMONG CO-AUTHORS: We used the preprint server medRxiv to post a systematic analysis of the development of therapeutic interventions for COVID-19 in order to stimulate diffusion of the manuscript and allow widespread "open source" input from co-authors (7). Successive versions of the preprint article have been posted periodically as a chronicle beginning in late May, 2020 and continuing to date (8). This process led to the present multinational consensus process involving 36 co-authors.

\section{RESULTS}


3.1 REVIEW OF CURRENT TRIALS: As of December 27, 2020, we identified 750 trials currently in recruitment phase with subject size of 100 or more (Supplementary Table 1). Of these, 122 were directed at prevention in healthy individuals, 100 were classified as treatment of outpatients with documented infection, and 390 were for treatment of hospitalized inpatients. There were 9 trials focusing on the post discharge Tail phase. The remaining trials were unclear as to intended subjects. Among the trials, there were 60 vaccine trials, 120 trials of hydroxychloroquine (HCQ), 33 trials of alternative therapy, 12 trials of colchicine, 38 trials of anticoagulants, 22 trials of the RNA polymerase inhibitor favipiravir (FVP), 19 trials of interferons, 18 trials of glucocorticoid, and 58 trials of plasma based products. Closure of enrollment was projected by the end of the year for 153 trials.

3.2 COMPLETED TRIALS: As of December 27, 2020, there were 97 trials reporting completion with 100 or more subjects( Supplementary Table 2 There were 52 trials in hospitalized patients, 9 directed at outpatients, and 12 prevention studies, the rest mixed.

3.3 PUBLISHED RESULTS ON COVID-19 TRIALS: As of December 27, 2020 we found 83 publications reporting findings in human studies on 14 classes of agents, and on 7 vaccines (See TABLE 1). There were 45 randomized or active controlled studies. The rest were retrospective observational analyses. Only 15 publications dealt with outpatient care, including 7 vaccine reports; the rest were all in hospitalized patients.

3.3.1 In the group of antiviral agents, the largest published randomized, controlled trials were with the intravenously administered RNA polymerase inhibitor remdesivir (9-13). A double blind, randomized placebo controlled trial of remdesivir, in 1062 moderate to severely ill patients was carried out by the National Institute of Allergy and Infectious Disease (NIAID) (10). The patients who received remdesivir had a median recovery time of 10 
days (95\% confidence interval [CI], 9 to 11), as compared with 15 days (95\% CI, 13 to 18) among those who received placebo (rate ratio for recovery, $1.29 ; 95 \%$ CI, 1.12 to $1.49 ; \mathrm{P}<0.001)$. $\mathrm{P}<0.001)$. The Kaplan-Meier estimates of mortality by 29 days after randomization were $11.4 \%$ with remdesivir and $15.2 \%$ with placebo (hazard ratio, 0.73 ; 95\% CI, 0.52 to 1.03 ). On the basis of this trial, the Food and Drug Administration (FDA) approved the use of remdesivir for COVID-19 hospitalized patients. A different study of remdesivir in hospitalized patients with moderate COVID19 clinical status showed improved clinical status by day 11 compared to standard of care for a 5 day course of remdesivir, but not for a 10 day course (12). There has been no data provided on viral clearance for the U.S. remdesivir studies. In early April, the WHO organized a megatrial, appropriately named Solidarity, to assess four separate treatment options only in hospitalized patients: (a) Remdesivir, an intravenously administered inhibitor of RNA polymerase; (b) The HIV agent lopanovir/ritanovir (LPV/R); (c) LPV/R plus Interferon $\beta$-1a; and (d) the antimalarials hydroxychloroquine (HCQ) and chloroquine (13). Results of the Solidarity Trial were reported by the World Health Organization on October 15, 2020. They found no effect of remdesivir on 28 day mortality, need for mechanical ventilation nor duration of hospitalization in a study including 5451 hospitalized patients (13).

3.3.2 There were two positive randomized, active control clinical trials in China of the orally administered RNA polymerase inhibitor favipiravir (FVP) $(14,15)$. In a trial comparing 116 patients on FVP to 120 on umifenovir, the 7 day clinical recovery rate was $55.9 \%$ for the umifenovir group and $71 \%$ in the FVP group (15). In Russia, a preliminary study of FVP showed reduced duration of viral shedding, and the drug was approved for clinical treatment beginning in multiple hospitals on June 12, 2020 (17). In a follow-up phase 3 study, they reported $27 \%$ clinical improvement at day 10 compared to $15 \%$ for standard care with $98 \%$ clearance of SARS-COV-2 compared to $79 \%$ (18). In India, a study of 150 mild to moderate COVID-19 patients showed median time to clinical cure of 3 days (95\% CI: 3 days, 4 days) for FVP versus 5 days (95\% CI: 4 days, 6 days) 
for control, $\mathrm{P}=0.030$, and FVP was approved to treat COVID-19 in July (19). In late September, a report, still unpublished, of a randomized controlled study in Japan announced more rapid viral clearance in FVP treated patients.

3.3.3 There have been many studies of HCQ (20-47). A group in Marseille reported their experience with 3737 patients screened positive for SARSCov-2 and immediately treated with HCQ and azithromycin (AZM), after excluding patients at risk of QT prolongation (20). They showed clearance of viral shedding in $89.4 \%$ of the patients by ten days. The overall mortality in their population was $0.9 \%$, none in patients under 60 years old, and no sudden cardiac deaths. They had no randomized control population, but their study prompted immediate widespread use of HCQ throughout the world for treatment of COVID-19 patients.

Subsequent randomized controlled studies in hospitalized patients have shown no clinical nor mortality benefit of HCQ. In the randomized RE-

COVERY trial in 1542 hospitalized patients in the United Kingdom, there was no significant difference in the primary endpoint of 28-day mortality (26.8\% HCQ vs. $25 \%$ usual care; hazard ratio 1.09 [95\% confidence interval $0.96-1.23] ; p=0.18$ ) (34). In the Solidarity Trial, there was no benefit of HCQ on mortality (HCQ RR=1.19 (0.89-1.59, p=0.23; 104/947 vs 84/906), need for mechanical ventilation, nor duration of hospitalization (13). However, in a retrospective comparison study at NYU Langone Health for all patients admitted between March 2 and April 5, 2020, there was a move to add zinc $100 \mathrm{mg}$ daily to their standard HCQ plus AZM regimen (35). There was a significantly lower mortality (13.1\%) among the zinc treated patients compared to those who did not receive zinc $(22.8 \%)$. 
There has been limited study of HCQ in outpatients. In one internet-based prevention study, with HCQ given for 5 days to healthy individuals with a significant exposure to SARS-Cov-2, the incidence of new illness compatible with COVID-19 did not differ significantly between participants receiving HCQ (49 of 414 [11.8\%]) and those receiving placebo (58 of 407 [14.3\%]); absolute difference -2.4 percentage points (95\% confidence interval, -7.0 to $2.2 ; p=0.35$ ) (36). The same group also treated 423 patients with mild symptoms imputed to COVID-19 (37). At 14 days, $24 \%$ (49 of 201) of participants receiving HCQ had ongoing symptoms compared with 30\% (59 of 194) receiving placebo ( $p=0.21)$.

A study in Spain of 293 patients with PCR-confirmed mild COVID-19, found no difference in viral load nor risk of hospitalization following 6 days of HCQ treatment compared to untreated patients (38). The same group treated 1,116 healthy contacts of 672 Covid-19 index cases with HCQ while 1,198 were randomly allocated to usual care (39). There was no significant difference in the primary outcome of PCR-confirmed, symptomatic Covid-19 disease (6.2\% usual care vs. 5.7\% HCQ; risk ratio 0.89 [95\% confidence interval 0.54-1.46]), nor evidence of prevention of SARS-CoV-2 transmission (17.8\% usual care vs. $18.7 \%$ HCQ).

A large population study in Portugal surveyed all patients on chronic HCQ treatment and cross-verified against a mandatory database of patients registered with COVID-19 (40). The incidence of a positive PCR test for SARS-CoV-2 infection in patients receiving HCQ was 5.96\%, compared to $7.45 \%$ in those not so treated, adjusted odds ratio $0.51(0.37-0.70)$. However, two separate randomized controlled studies found no evidence of benefit of two months prophylactic treatment of hospital workers with HCQ $(41,42)$.

3.3.4. Published results with Lopanovir/ritonavir (LPV/r) have been disappointing $(13,43-45)$. In a randomized trial with 99 patients on LPV/r and 100 receiving standard care, there was no difference in time to clinical improvement, mortality nor viral clearance (44). In the RECOVERY trial in 
1,596 hospitalized patients there was no significant difference in the primary endpoint of 28-day mortality (22.1\% LPV/r vs. $21.3 \%$ usual care; relative risk 1.04 [95\% confidence interval 0.91-1.18]; $(p=0.58)$ (45). In the Solidarity Study, there was no effect of LPV/r on 28 day mortality LPV/r $\mathrm{RR}=1.00(0.79-1.25, \mathrm{p}=0.97 ; 148 / 1399$ vs $146 / 1372)$, need for mechanical ventilation nor duration of hospitalization (13).

A possibly more favorable result was obtained in Hong Kong in a study of 86 patients assigned to triple combination therapy with LPV/r plus ribavirin plus interferon $\beta-1$ (46). Compared to a control group of 41 patients receiving LPV/r alone, the combination group had a significantly shorter median time from start of study treatment to negative SARS-Cov-2 nasopharyngeal swab (7 days [IQR 5-11]) than the control group (12 days [815]; hazard ratio 4.37 [95\% CI 1.86-10.24], $p=0 \cdot 0010)$. The time to complete alleviation of symptoms was 4 days [IQR 3-8] in the combination group vs 8 days [7-9] in the control group; HR 3.92 [95\% CI 1.66-9.23. This study was interpreted not as supporting LPV/r therapy, but rather focusing on interferon $\beta-1$ as the primary treatment modality.

3.3.5 Interferon studies have been encouraging. In Cuba, a combination of interferon- $\alpha-2 b$ and interferon $\gamma$ on background therapy of LPV/r and chloroquine was successful in achieving viral clearance in 4 days in $78.6 \%$ of the patients compared to $40.6 \%$ of those receiving interferon- $\alpha-2 b$ alone (49). In the Solidarity Study in hospitalized patients, there was no effect of injected interferon on 28 day mortality (IFN RR=1.16 (0.96-1.39, $\mathrm{p}=0.11 ; 243 / 2050$ vs 216/2050), need for mechanical ventilation nor duration of hospitalization (13). However, a separate trial of nebulized interferon $\beta$-1 reported positive improvement in clinical status (52). 
3.3.6 There have been many observational studies of immunomodulatory therapy with the IL-6 inhibitor tocilizumab and the IL-1 inhibitor anakinra to mitigate the pulmonary phase of COVID-19 suggesting reduction of mortality and need for intubation in hospitalized severe and critically ill patients (28, 53-66). However, in several randomized control studies, there has been no benefit with tocilizumab (67-69). In the COVACTA trial, there was no benefit of tocilizumab in clinical status, mortality $(19.7 \%$ tocilizumab vs placebo $=19.4 \%)$, nor in ventilator free days $(68)$, and in the Cor-Immuno-Toci trial, no decrease in mortality at day 28 (69). The tocilizumab results in these randomized controlled trials were affected by a higher frequency of glucocorticoid use in the control groups.

3.3.7 Pre-COVID-19, glucocorticoid treatment had been a recognized treatment with mortality benefit for patients in severe respiratory distress (70). Dexamethasone has now demonstrated benefit in several COVID-19 hospital trials (71-72). In the RECOVERY trial, 2104 patients were randomly allocated to receive dexamethasone for ten days compared to 4321 patients concurrently allocated to usual care (72). Overall, 454 (21.6\%) patients randomized to dexamethasone and 1065 (24.6\%) patients receiving usual care died within 28 days (age adjusted rate ratio [RR] 0.83; 95\% confidence interval $[\mathrm{CI}] 0.74$ to $0.92 ; p<0.001)$. Dexamethasone reduced deaths by one-third in the subgroup of patients receiving invasive mechanical ventilation $(29.0 \%$ vs. $40.7 \%$, RR 0.65 [95\% CI 0.51 to 0.82 ]; $p<0.001)$ and by one-fifth in patients receiving oxygen without invasive mechanical ventilation $(21.5 \%$ vs. $25.0 \%$, RR 0.80 [95\% CI 0.70 to 0.92$]$; $p=0.002)$, but did not reduce mortality in patients not receiving respiratory support at randomization (17.0\% vs.13.2\%, RR 1.22 [95\% CI 0.93 to 1.61]; $p=0.14$ ). Most trials of other glucocorticoids have shown similar benefits in COVID19 patients with acute respiratory failure (73-80) 
3.3.8 There is promising data on convalescent plasma (81-86). A meta-analysis including 4173 patient outcomes across a multinational series of studies concluded that convalescent plasma treatment yielded a 57\% reduction in mortality (85). The reduction was greatest in patients treated within 3 days of diagnosis with high titer antibody plasma. Based on evidence of safety in over 20,000 patients in an expanded access program coordinated by the Mayo Clinic, the U.S. FDA recently issued an emergency authorization for use of convalescent plasma (86). Monoclonal antibodies to the SARS-COV-2 spike protein have been synthesized. Treatment of ambulatory patients with the LY-CoV555 neutralizing antibody and the Regeneron combination of two antibodies early in the course of infection has shown success in reducing the frequency of hospitalization, and the FDA issued an emergency authorization for use in outpatients (88).

3.3.9 There have been a number of reports on agents not ordinarily considered as antivirals. These include famotidine, nitazoxanide, fluvoxamine, colchicine, and ivermectin (89-96). Colchicine, an anti-inflammatory agent, suggested benefit in the GRECCO, placebo-controlled, randomized clinical trial of 105 patients (90). The primary clinical end point of deterioration to mechanical ventilation or death was $14 \%$ in the control group (7 of 50 patients) and $1.8 \%$ in the colchicine group ( 1 of 55 patients) (odds ratio, $0.11 ; 95 \% \mathrm{CI}, 0.01-0.96 ; \mathrm{p}=0.02$ ). There have now been a number of trials including several randomized controlled studies suggesting benefit with ivermectin both in prevention and in treatment of COVID-19 (TABLE $1)$.

3.3.10 A number of vaccines have reported successful induction of neutralizing antibody and cellular immune responses in early phase trials (98104). The Moderna and Pfizer Biontech mRNA spike protein vaccines released data showing over $90 \%$ effectiveness at preventing symptomatic infection in a 2 month post immunization observation period, and emergency authorization for immunization has been given. Massive vaccinations have begun in many countries. 


\section{CONCLUSION}

SARS-Cov-2 fueled by modern day jet travel overwhelmed medical preparedness for the pandemic. Current projections are for a continuation of new cases and deaths continuing in $2021(105,106)$. On December 31, 2020, 470,046 new cases were reported worldwide (1). Of these 174, 814 cases occurred in the United States. Clinical trials to date have focused primarily on hospitalized patients to try to prevent death. It is hoped that the use of remdesivir, convalescent plasma, glucocorticoids, anticoagulation and improved management of COVID-19 respiratory failure will lower the present rate of in hospital mortality which in some series has been as low as $6 \%$ but in most hospitals still approaches $20 \%$ (77). However, it is essential to change the present dynamic of attempted therapeutic responses to recognize specific phases of the disease (107). In particular, efforts must now focus on prevention and treatment of the initial viral infection so that hospitalization can be avoided. We face a dilemma with inadequate current prevention and treatment for outpatients with mild to moderate disease, constituting $80 \%$ of the infected population and the primary mode of spread of SARS-Cov-2. The lessons learned in very sick hospitalized patients do not necessarily apply to the earlier viremic phase. Antiviral agents, such as remdesivir and favipiravir, interferon, convalescent plasma, and monoclonal antibodies are likely to be most effective during the early stage of viremia, which is prior to the pulmonary phase requiring hospitalization.

Vaccines have been the solitary hope held out by public health authorities to arrest SARS-Cov-2. Progress on vaccine development has been rapid, but the speed of development does not reduce the challenges of developing vaccines to be administered to the population of the entire World. Although neutralizing antibodies and memory T cells can be produced by the vaccine candidate, the demonstration of true protection requires long-term 
follow-up of an exposed vaccinated population. The current vaccines will be released for emergency use after only a short two month period of observation. No matter how rapidly a vaccine advances to Phase III testing, the duration of follow-up cannot be shortened, and for SARS-Cov-2 possibly prolonged due to several factors. First, there is a risk of immune enhancement of infection which occurs when induced antibodies increase entry and internalization of virus into myeloid cells (108). This major complication struck the newly developed dengue vaccine in 2017 (109). Second, the sinister autoimmune pathogenicity of SARS-Cov-2 raises the risk of delayed long-term harm if the virus is not fully and immediately eradicated by the initial immune response to the vaccine. Furthermore, studies of recurrent coronavirus infections suggest that infection may confer immunity for less than a year (110). After implementation of a new vaccine, efforts to find volunteers for trials of new, more effective vaccines will be hampered if there is no treatment available for placebo treated patients who become infected. Vaccines are specific to the intended pathogen. There is the risk that the virus will mutate to a form for which the new vaccine may not be fully protective. Already two variants have emerged and caused major outbreaks. The level of protection offered by the current vaccines is currently under study. Finally, the degree of acceptance of the COVID-19 vaccines by the general population is questionable. Seasonal influenza vaccination coverage was only $48 \%$ in 2019 (111). Children typically have limited COVID-19 symptoms. However, they may serve as a reservoir of ongoing infectivity (112). Currently there have been no clinical trial results of vaccine in children.

It also follows that totally new viruses may emerge just as did SARS-Cov-2. COVID-19 is now the sixth severe viral epidemic to hit mankind in the past 20 years; certainly it has been more widespread than SARS-Cov-1, H1N1 influenza, MERS, Zika, and Ebola, but that does not diminish the gravity of these repeated viral threats. Development of antigen specific vaccines takes a long time during which disease takes a large toll as has been the case for SARS-Cov-2. The succession of viral afflictions points to the need to implement widespread use of antiviral agents. The current recom- 
mendation for COVID-19 is home quarantine with no specific treatment for patients with suspicious symptoms. What is needed is therapeutic intervention which can be used to treat all outpatients with positive COVID-19 tests at the time of initial symptoms, not waiting for deterioration requiring hospital care. Hydroxychloroquine has not succeeded. Remdesivir administered intravenously for five days is not a practical daily outpatient treatment; Gilead $\odot$ is attempting to develop an inhaled remdesivir formulation, but those efforts are only now beginning. Favipiravir, a tablet, could be used in early stages of infection and has now been released in Russia, Hungary, and in India, but not in the United States and the European Union. It has known embryogenic risks, so its use requires restrictions on women of childbearing potential, as is the case with tretinoin for acne and thalidomide for multiple myeloma. Trials with camostat, the serine protease inhibitor, capable of blocking cell entry of SARS-Cov-2, are not due to end till the fourth quarter of the year. Similarly, a prevention trial with colchicine is not scheduled to end until the fourth quarter of 2020 . Convalescent plasma is used primarily in hospital patients. Monoclonal antiviral neutralizing antibodies based on the same principle have finally received emergency use authorization for ambulatory patients. However, the scale of production of these monoclonal antibodies is far too limited to offer to all outpatients who should be treated. Interferon formulations have shown promise in several studies. There have been several randomized controlled studies suggesting benefit with ivermectin both for prophylaxis and treatment.

Yet, at this time, no outpatient therapy has been proven safe and effective in large scale phase III randomized, placebo-controlled studies. There are strong arguments to avoid emergency use of agents until trials are completed and analyzed, but the agents suggested are not new. Most are drugs like ivermectin, colchicine, and the interferons, marketed and available for other conditions and with well-known safety profiles. There is a clear need to offer outpatient therapeutic intervention now to the World's population. 
There is a precedent to resolve the conflict between immediate clinical need and the requirements for rigorous controlled trials to prove efficacy. We should remember that the greatest success in fighting a pandemic occurred over the past two decades in the battle against the HIV virus which causes AIDS. AIDS was first recognized in 1981 in the MSM (men who have sex with men) community. The disease was considered a death sentence. There was widespread fear because there was no treatment, and projections of infection escalated into the millions. The first AIDS remedy was azidothymidine (AZT), synthesized in 1964 in the hope that it would combat cancer. Twenty years later Dr. Samuel Broder, head of the National Cancer Institute, showed that the drug had activity against the HIV virus in vitro (113). Burroughs Wellcome launched a rapidly conceived trial with just 300 patients. They stopped the trial in 16 weeks claiming that more patients survived on AZT. The FDA came under enormous pressure from AIDS activists to make the drug available, and it was approved on March 19, 1987, with only that one trial. It had taken 20 months for the FDA to give approval to release the drug. To this day, the design and results of the trial remain controversial.

The LGBT community continued to battle for early release of other medications to combat the AIDS pandemic. On October 11, 1988, a massive protest occurred at the FDA. It was back then Dr. Anthony Fauci who publicly advanced the idea of a parallel track to make drugs widely available even while studies are progressing: "Clearly, the standard approach to the design of clinical trials-that is, rigid eligibility criteria as well as the strict regulatory aspects that attend clinical trial investigations and drug approval —was not well-suited to a novel, largely fatal disease such as this with no effective treatments, and we had many intense discussions about how to make that approach more flexible and ethically sound. One example, which I and others worked closely with the AIDS activists to develop, was called a parallel track for clinical trials. The parallel track concept, which the United States Food and Drug Administration ultimately came to support, meant that there would be the standard type of highly controlled admission criteria and data collection for the clinical trial of a particular drug. In parallel, however, the drug also could be made available to those who 
did not meet the trial's strict admission criteria but were still in dire need of any potentially effective intervention, however unproven, for this deadly disease" (114).

The parallel track advocated by Dr. Fauci was adopted. Today, there are 41 drugs or combinations approved by the FDA to treat and to prevent HIV infection. There is still no vaccine. There are now an estimated 1.1 million patients with HIV in the United States, most enjoying near normal life expectancy thanks to the antiviral agents. The CDC has contributed greatly to limit the spread of HIV by advocating safe sex practices, but social distancing is not the norm for HIV. Rather "treatment as prevention" for people with HIV using highly active antiretroviral regimens to prevent transmission as well as pre-exposure prophylaxis with a daily antiviral combination pill are currently endorsed by the CDC and adopted in wide segments of the at risk population (115).

In this pandemic crisis, we appeal to public health authorities to change the dynamic of current studies to outpatient care and to cross institutional, commercial and international boundaries to collate and combine all randomized controlled data submitted for all agents in Europe, China, Russia, Japan, India and other countries, and by competing companies, whether officially published, posted on line, or unpublished to finalize confirmatory results. The Solidarity Trial is a model of what could and should be done to unify a worldwide effort to pursue randomized controlled studies in outpatients. At the same time, agents with favorable preliminary results and no safety issues should be made available through a parallel track. In Russia and India, the parallel track has been fully implemented, with FVP now offered as treatment throughout both countries, even as further confirmatory controlled trials proceed. Interferon formulations are now approved treatments in China and Cuba. It is reasonable to authorize vaccination in very large parallel track studies in at risk populations, such as healthcare workers and the elderly. At this time, with no other option available, vaccination will have to be universal, despite the need to perform controlled studies to develop improved vaccines. However, it is unwise to rely 
solely on the hope for eventual mass vaccination to stop SARS-Cov2. Antiviral medication has succeeded in limiting HIV and hepatitis, and antivirals are just as important as annual vaccination for control of influenza. It is necessary for public health authorities to make hard decisions now despite limited current data and offer outpatient treatments on a broad front with no further delay.

\section{REFERENCES}

1) WHO Coronavirus Disease (COVID-19) Dashboard

Data last updated: 2021 January $111 \mathrm{am}$.

2) Wu Z, McGoogan JM. Characteristics of and important lessons from the coronavirus disease 2019 (COVID-19) outbreak in China. Summary of a report of 72314 cases from the Chinese Center for Disease Control and Prevention. JAMA 2020; 323: 1239-1242

3) Chen T, Wu D, Chen H, et al. Clinical characteristics of 113 deceased patients with coronavirus disease 2019: retrospective study. BMJ. 2020;368:m1091.

4) Connors JM, Levy JH. Thromboinflammation and the hypercoagulability of COVID-19. 
J Thromb Haemost. 2020 Apr 17 https://doi.org/10.1111/jth.14849.

5) Ricardo J, Manuel A. COVID-19 cytokine storm: the interplay between inflammation and coagulation storm: Lancet Respir Med 2020; 8(6): e46-e47

6) Thorlund KT, Dron L, Park J et al. A real-time dashboard of clinical trials for COVID-19. Lancet Digital Health 2020; 2: e86-e87 published on line 24 Apr 20 https://doi.org/10.1016/ S2589-7500(20)30086-8

7) Ngo BT, Rendell M. A systematic analysis of the time course to develop treatments for COVID-19medRxiv 2020.05.27.20115238; doi: https://doi.org/10.1101/2020.05.27.20115238

(8) Ngo BT, Marik P, Kory P, et al. The time to offer treatments for COVID-19. medRxiv, 16 Dec20 doi: https://doi.org/10.1101/2020.05.27.20115238

9) Wang Y, Zhang D, Guanhua Du G, et al. Remdesivir in adults with severe COVID-19: a randomised,double-blind, placebo-controlled, multicentre trial. Lancet 2020; 395 (10236): 1569-1578 
10) Beigel JH, Tomashek KM, Dodd LE et al. Remdesivir for the Treatment of Covid-19 — final Report. October 8, 2020 DOI:

10.1056/NEJMoa2007764

11) Goldman JD, Lye DCB, Hui DS, et al. Remdesivir for 5 or 10 days in patients with severe Covid-19. New Engl J Med May 27, 2020 DOI:

10.1056/NEJMoa2015301

12) Spinner CD, Gottlieb RL, Criner GJ et al. Effect of remdesivir vs standard care on clinical status at 11 days in patients with moderate COVID-

19. A randomized clinical trial .JAMA. Published online August 21, 2020. doi:10.1001/jama.2020.16349

13) WHO Solidarity trial consortium. Repurposed antiviral drugs for COVID-19 -interim WHO SOLIDARITY trial results. medRxiv 2020. .https://doi.org/10.1101/2020.10.15.20209817 posted Oct 15, 2020

14) Cai Q, Yang M, Liu D, et al. Experimental treatment with favipiravir for COVID-19: An open-label control study Engineering (Beijing). 2020;10.1016/j.eng.2020.03.007. doi:10.1016/j.eng.2020.03.007

15) Chen C, Huang J, Zhenshun Cheng Z, et al. Favipiravir versus Arbidol for COVID-19: A randomized clinical trial. medRxiv preprint doi: https://doi.org/10.1101/2020.03.17.20037432.this version posted March 20, 2020. 
16) Preliminary Report of the Favipiravir Observational Study in Japan Favipiravir Observational Study Group.

http://www.kansensho.or.jp/uploads/files/topics/2019ncov/ covid19_casereport_en_200529.pdf Accessed 19 June 2020

17) Ivashchenko AA, Dmitriev KA, Vostokova NV, et al. AVIFAVIR for treatment of patients with moderate COVID-19: Interim results of a Phase II/III multicenter randomized clinical trial. Clinical Infectious Diseases, ciaa1176, https://doi.org/10.1093/cid/ciaa1176

18) https://clinicaltrials.gov/ct2/show/NCT04542694: Study of Favipiravir Compared to Standard of Care in Hospitalized Patients With COVID-19.

Results posted 9 Nov 2020

19) Udwadia ZF, Singh P, Barkate H, et al. Efficacy and safety of favipiravir, an oral RNA-dependent RNA polymerase inhibitor, in mild-tomoderate COVID-19: A randomized,comparative, open-label, multicenter, phase 3 clinical trial. Int J Infec Disease (In Press)

20) Lagier JC, Million M, Gautret P, et al. Outcomes of 3,737 COVID-19 patients treated with hydroxychloroquine/azithromycin and other regimens in Marseille, France: A retrospective analysis. Travel Med Infect Dis. 2020 July-August; 36: 101791. . Available on line 25 June 2020

21) Chen Z, Hu J,Zhang Z, et al. Efficacy of hydroxychloroquine in patients with COVID-19: results of a randomized clinical trial. medRxiv preprint doi:https://doi.org/10.1101/2020.03.22.20040758.this version posted March 30, 2020.

22) Chen J, Liu D, Liu L, et al. A pilot study of hydroxychloroquine in treatment of patients with common coronavirus disease-19 (COVID-19) J

Zhejiang Univ (Med Sci) 2020, Vol. 49 Issue (1): 0-0 DOI: 10.3785/j.issn.1008-9292.2020.03.03 
23) Tang W, Cao Z, Han M, et al. Hydroxychloroquine in patients mainly with mild to moderate COVID-19: an open-label, randomized, controlled trial. BMJ 2020;369:m1849

24) Magagnoli J, Narendran S, Pereira F, et al. Outcomes of hydroxychloroquine usage in United States veterans hospitalized with COVID-19. Med (2020), https://doi.org/10.1016/ j.medj.2020.06.001

25) Geleris J, Sun Y, Platt J, et al. Observational study of hydroxychloroquine in hospitalized patients with Covid-19. New Engl J Med $2020 ; 382(25): 2411-2418$

26) Rosenberg ES, Dufort EM, Udo T, et al. Association of treatment with hydroxychloroquine or azithromycin with in-hospital mortality in patients with COVID-19 in New York State. JAMA 2020; 323(24): 2493-2502.

27) Mahévas M, Tran VT, Roumier M, et al. Clinical efficacy of hydroxychloroquine in patients with covid-19 pneumonia who require oxygen: observational comparative study using routine care data. BMJ 2020;369:m1844

28) Ip A, Berry DA, Hansen E, et al, Hydroxychloroquine and tocilizumab therapy in COVID-19 patients - An observational study. PLoS ONE 15(8): e0237693. 
29) Arshad S, Kilgore P, Chaudhry ZS, et al. Treatment with hydroxychloroquine, azithromycin, and combination in patients hospitalized with COVID-19. Int J Inf Dis. 2020 ; 97: 396-403

30) Cavalcanti AB. Zampieri FG, Rosa RG, et al .Hydroxychloroquine with or without azithromycin in mild-to-moderate Covid-19. New Eng J Med published on line July 23, 2020 DOI: 10.1056/NEJMoa2019014

31) Furtado RHM, Berwanger O*, Fonseca HA,et al Azithromycin in addition to standard of care versus standard of care alone in the treatment of patients admitted to the hospital with severe COVID-19 in Brazil (COALITION II): a randomised clinical trial. Lancet 2020; 396: 959-67

32) Borba MGS, Val FFA, Sampaio VS, et al. Effect of high vs low doses of chloroquine diphosphate as adjunctive therapy for patients hospitalized with severe acute respiratory syndrome coronavirus 2 (SARS-CoV-2) infection: A randomized clinical trial. JAMA Netw Open . 2020 Apr 24;3e208857. doi: 10.1001/jamanetworkopen.2020.8857,

33) Self WH, Semler MW, Leither LM, et al Effect of hydroxychloroquine on clinical status at 14 days in hospitalized patients with COVID-19 A randomized clinical trial JAMA. Published online November 9, 2020. doi:10.1001/jama.2020.22240

34) RECOVERY Collaborative Group. Effect of Hydroxychloroquine in hospitalized patients

with COVID-19. New Engl J Med October 8, 2020 DOI: 10.1056/NEJMoa2022926 
35) Carlucci P, Tania Ahuja T, Petrilli CM, et al. Hydroxychloroquine and azithromycin plus zinc vs hydroxychloroquine and azithromycin alone: outcomes in hospitalized COVID-19 patients medRxiv doi: https://doi.org/10.1101/2020.05.02.20080036

36) Boulware DR, Pullen MF, Bangdiwala AS, et al. A randomized trial of hydroxychloroquine as postexposure prophylaxis for Covid-19. N Engl J Med J 2020; 383:517-525

37) Skipper CP, Pastick KA, Engen NW, et al. Hydroxychloroquine in nonhospitalized adults with early COVID-19.A randomized trial. Ann Int Med 2020 Jul 16 : M20-4207

38) Mitjà O, Corbacho-Monné M, Ubals M, et al. Hydroxychloroquine for early treatment of adults with mild Covid-19: a randomized-controlled trial. Clinical Infectious Diseases, ciaa1009, https://doi.org/10.1093/cid/ciaa1009 Published: 16 July 2020

39) Mitjà $\mathrm{O}$, Ubals $\mathrm{M}$, Corbacho-Monné $\mathrm{M}$, et al. A cluster-randomized trial of hydroxychloroquine as prevention of Covid-19 transmission and disease. medRxiv 2020.07.20.20157651; doi: https://doi.org/10.1101/2020.07.20.20157651

40) Ferreira A, Oliveira-e-Silva A ,Bettencourt P. Chronic treatment with hydroxychloroquine and SARS-CoV-2 infection. J Med Virol 2020:1-5J Med Virol. 2020;1-5 DOI: 10.1002/jmv.26286 
41) Abella BS, Jolkovsky EL, Biney BT, et al. Efficacy and safety of hydroxychloroquine vs placebo for pre-exposure SARS-CoV-2 prophylaxis among health care workers. A randomized clinical trial

JAMAInternMed.doi:10.1001/jamainternmed.2020.6319 PublishedonlineSeptember30,2020.

42) Rajasingham R, Bangdiwala AS, Nicol MR, et al. Hydroxychloroquine as pre-exposure prophylaxis for COVID-19 in healthcare workers: a randomized trial. Preprint. medRxiv. 2020;2020.09.18.20197327. Published 2020 Sep 18. doi:10.1101/2020.09.18.20197327

43) Li Y, Xie Z, Lin W, et al. An exploratory randomized, controlled study on the efficacy and safety of lopinavir/ritonavir or arbidol treating adult patients hospitalized with mild/moderate COVID-19 (ELACOI.Med (N Y). 2020 May 19 doi: 10.1016/j.medj.2020.04.001

44) Cao B, Wang Y, Wen D, et al. A Trial of Lopinavir-Ritonavir in adults hospitalized with severe Covid-19. N Engl J Med. 2020;382(19):17871799.

45) RECOVERY Collaborative Group. Lopinavir-ritonavir in patients admitted to hospital with COVID-19 (RECOVERY): a randomised, controlled, open-label, platform trial. Lancet Published Online October 5. 2020 https://doi.org/10.1016/ S0140-6736(20)32013-4. 
46) Hung IFN , Lung KC, Tso EYK et al Triple combination of interferon beta-1b, lopinavir-ritonavir, and ribavirin in the treatment of patients admitted to hospital with COVID-19: an open-label, randomised, phase 2 trial Lancet,2020 May 30;395(10238):1695-1704.

47) Estebanez M, Ramirez-Olivencia G, Mata T, et al. Clinical evaluation of IFN beta-1-b in COVID-19 pneumonia: a retrospective study. MedRxiv doi: https://doi.org /10.1101/ 2020.05.15.20084293

48) Pereda R, González D, Rivero HB, et al. Therapeutic effectiveness of interferon-alpha 2b against COVID-19: the Cuban experience. medRxiv preprint doi: https:// doi.org/10.1101/ 2020.05.29.20109199.

49) PE Idelsis, Perez-Escribano J, Duncan-Robert $Y$, et al Effect and safety of combination of interferon alpha-2b and gamma or interferon alpha-2b for negativization of SARS-CoV-2 viral RNA medRxiv https://doi.org/10.1101/2020.07.29.20164251

50) Rahmani H, Davoudi-Monfared E, Nourian A, et al. Interferon $\beta$-1b in treatment of severe COVID-19: A randomized clinical trial. Int Immunopharmacol. 2020 Nov; 88: 106903. Published online 2020 Aug 24. doi: 10.1016/j.intimp.2020.106903

51) Meng Z, Wang T, Chen L, et al. An experimental trial of recombinant human interferon alpha nasal drops to prevent COVID-19 in medical staff in an epidemic area. medRxiv .https://doi.org/10.1101/ 2020.04.11.20061473 
52) Monk PD, Marsden RJ, Tear VJ, et al. Safety and efficacy of inhaled nebulised interferon beta-1a (SNG001) for treatment of SARS-CoV-2 infection: a randomised, double-blind, placebo-controlled, phase 2 trial. Lancet Respir Med 2020Published OnlineNovember 12, 2020 https://doi.org/10.1016/S2213-2600(20)30511-7

53) Xua X, Hanb M, Lia T, et al. Effective treatment of severe COVID-19 patients with tocilizumab 10970-10975 | Proc Natl Acad Sci | May 19, 2020 | vol. 117 | no. 20 www.pnas.org/cgi/doi/10.1073/pnas.2005615117

54) Somers EC, Eschenauer GA, Troost JP. Tocilizumab for treatment of mechanically ventilated patients with COVID-19. MedRxiv doi: https://doi.org/10.1101/2020.05.29.20117358

55) Rossi B, Nguyen LS, Zimmermann, et al. Effect of tocilizumab in hospitalized patients with severe pneumonia COVID-19: a cohort study medRxiv doi: https://doi.org/ 10.1101/2020.06.06.20122341

56) Martinez-Sanz J, Muriel A, l Ron R, et al. Effects of tocilizumab on mortality in hospitalized patients with COVID-19: A Multicenter Cohort Study. MedRxiv doi: https://doi.org/10.1101/2020.06.08.20125245 
57) Petrak R, Skorodin N, Van Hise N, et al. Tocilizumab as a therapeutic agent for critically ill patients infected with SARS-CoV-2. MedRxiv doi: https://doi.org/10.1101/ 2020.06.05.20122622

58) Perrone P, Piccirillo MC, Ascierto PA, et al. Tocilizumab for patients with COVID-19 pneumonia. The TOCIVID-19 phase 2 trial. MedRXiv doi: https://doi.org/10.1101/2020.06.01.20119149

59) Garcia EM, Caballero VR, Albiach L,et al. Tocilizumab is associated with reduction of the risk of ICU admission and mortality in patients with SARS-CoV-2 infection medRxiv doi: https://doi.org/ 10.1101/2020.06.05.20113738

59) Wadud N, Ahmed N, Shergil M, et al. Improved survival outcome in SARs-CoV-2 (COVID-19) acute respiratory distress syndrome patients with tocilizumab administration. MedRxiv doi: https://doi.org/10.1101/2020.05.13.20100081

60) Sanchez-Montalva A, Selares-Nadal J, Espinosa-Pereiro J, et al. Early outcomes of tocilizumab in adults hospitalized with severe COVID19. An initial report from the Vall dHebron COVID19 prospective cohort study.doi: https://doi.org/10.1101/2020.05.07.20094599

61) Ramaswamy M, Mannam P, Comer R, et al. Off-label real world experience using tocilizumab for patients hospitalized with COVID-19 disease in a regional community health system: A case-control study medRxiv. doi: https://doi.org/10.1101/2020.05.14.20099234 
62) Guaraldi G, Meschiari M, Cozzi-Lepri A, et al. Tocilizumab in patients with severe COVID-19: a retrospective cohort study. Lancet Rheumatol 2020; 2(8): 2, e474-e484

63) Cavalli G, De Luca G, Campochiaro C, et al. Interleukin-1 blockade with high-dose anakinra in patients with COVID-19, acute respiratory distress syndrome, and hyperinflammation: a retrospective cohort study. Lancet Rheumatol 2020; 2: e325-31

64) Cauchois R, Koubia M, Delarbreb D, et al. Early IL-1 receptor blockade in severe inflammatory respiratory failure complicating COVID-19. Proc Nat Acad Sci 2020; 117: 18951-18953

65) Huet T, Beaussier H, Voisin O, et al. Anakinra for severe forms of COVID-19: a cohort study. Lancet Rheumatol 2020; 2: e393-e400

66) Kyriazopoulou E, Panagopoulos P, Metallidis S, et al. Anakinra to prevent respiratory failure in COVID-19.medRxiv preprint doi: https://doi.org/10.1101/2020.10.28.20217455; this version posted October 29, 2020.

67) Salvarani C. Dolci G, Massari M et al. Effect of tocilizumab vs usual care in adults hospitalized with COVID-19 and moderate or severe pneumonia JAMA Intern Med. Published online October 20, 2020. doi:10.1001/jamainternmed.2020.6615 
68) Rosas IO, Bräu N,, Waters M, et al. Tocilizumab in hospitalized patients with COVID-19 pneumonia posted September $12,2020$. medRxiv.https://doi.org/10.1101/2020.08.27.20183442doi:

69) Hermine O, Mariette X, Tharaux PL, et al. Effect of tocilizumab vs usual care in adults hospitalized with COVID-19 and moderate or severe pneumonia. A randomized clinical trial Published Online: October 20, 2020. doi:10.1001/jamainternmed.2020.6820

70) Villar J, Ferrando C, Martínez D et al. Dexamethasone treatment for the acute respiratory distress syndrome: A multicentre, randomised controlled trial. Lancet Respir Med. 2020;8(3):267-276

71) Tomazini BM, Maia IS, Cavalcanti AB, et al. Effect of dexamethasone on days alive and ventilator-free in patients with moderate or severe acute respiratory distress syndrome and COVID-19: The CoDEX Randomized Clinical Trial. 2020 ;324(13):1307-1316.

72) RECOVERY Collaborative Group. Effect of Dexamethasone in Hospitalized Patients with COVID-19 - Preliminary Report. July 17, 2020 DOI: 10.1056/NEJMoa2021436

73) Salton F, Confalonieri P, Santus P, et al. Prolonged low-dose methylprednisolone in patients with severe COVID-19 pneumonia. Open Forum Infectious Diseases, Volume 7, Issue 10, October 2020, ofaa421, https://doi.org/10.1093/ofid/ofaa421 
74) Fadel R, Morrison AR, Vahia A, et al. Early short-course corticosteroids in hospitalized patients with COVID-1. Clinical Infectious Diseases 2020; ciaa601, https://doi.org/10.1093/cid/ciaa601

75) Villar J, Confalonieri, M, Pastore, SM, et al. Rationale for prolonged corticosteroid treatment in the acute respiratory distress syndrome caused by Coronavirus Disease 2019. Crit Care Explor April 2020;2 :e0111

76) Marik PE, Kory P, Varon J, et al. MATH+ protocol for the treatment of SARS-CoV-2 infection: the scientific rationale, Expert Review of Antiinfective Therapy https://doi.org/10.1080/14787210.2020.1808462 published on line 18 aug 2020

77) Chroboczek T, Lacoste L, Wackenheim C, et al. Beneficial effect of corticosteroids in severe COVID-19 pneumonia: a propensity score matching analysis. MedRxiv: doi: https://doi.org/ 10.1101/2020.05.08.20094755

78) Jeronimo CMP, Farias MEL, BSc, Val FFA, et al. Methylprednisolone as adjunctive therapy for patients hospitalized with COVID-19 (Metcovid): A randomised, double-blind, phase iib, placebo-controlled trial. Clinical Infectious Diseases, ciaa1177, https://doi.org/10.1093/cid/ciaa1177

79) Dequin PF, Heming NMD, Mezian F, et al; Effect of hydrocortisone on 21-day mortality or respiratory support among critically ill patients with COVID-19, A randomized clinical trial JAMA. 2020;324(13):1298-1306. doi:10.1001/jama.2020.16761 
80) Derek C Angus DC , Derde L 34 , Farah Al-Beidh F. Effect of hydrocortisone on mortality and organ support in patients with severe COVID-

19: The REMAP-CAP COVID-19 Corticosteroid Domain Randomized Clinical Trial. JAMA . 2020 Oct 6;324(13):1317-1329. doi:

10.1001/jama.2020.17022

81) Li L, Zhang W, Hu Y, et al. Effect of convalescent plasma therapy on time to clinical improvement in patients with severe and life-threatening COVID-19: a randomized clinical trial. JAMA

$2020 ; 324(5): 460-470$.

82) Perotti C, Baldanti F, Bruno R, et al. Mortality reduction in 46 severe Covid-19 patients treated with hyperimmune plasma. A proof of concept single arm multicenter interventional trial.

Haematologica. 2020 Jul 23;haematol.2020.261784. doi: 10.3324/haematol.2020.261784

83) Avendano-Sola C, Ramos-Martinez A,Munez-Rubio E, et al. Convalescent Plasma for COVID-19: A multicenter, randomized clinical trial. MedRxiv September 1, 2020. .https://doi.org/10.1101/2020.08.26.20182444doi: 
84) Rogers R, Shehadeh F, Mylona E, et al. Convalescent plasma for patients with severe COVID-19: a matched cohort study medRxiv 2020.08.18.20177402; doi: https://doi.org/10.1101/2020.08.18.20177402

85) Joyner MJ, Klassen SA, Senefeld JW, et al. Evidence favouring the efficacy of convalescent plasma for COVID-19 therapy. MedRxiv posted August 28, 2020.https://doi.org/10.1101/2020.07.29.20162917doi: medRxiv pr

86) Joyner MJ, Bruno KA, Klassen SA, et al, Safety update: COVID-19 convalescent plasma in 20,000 hospitalized patients Mayo Clin Proc. 2020;95 (9):1888-1897

87) Agarwal A, Mukherjee A, Kumar G, et al. Convalescent plasma in the management of moderate covid-19 in adults in India: open label phase II multicentre randomised controlled trial (PLACID Trial)

BMJ 2020;371:m3939 http://dx.doi.org/10.1136/bmj.m3939

88) Chen P, Nirula A, Heller B et al. SARS-CoV-2 neutralizing antibody LY-CoV555 in outpatients with Covid-19 October 28, 2020 , at NEJM.org. DOI: 10.1056/NEJMoa2029849 
89) Freedberg DE, Conigliaro J, Sobieszczyk ME, et al. Famotidine use is associated with improved clinical outcomes in hospitalized COVID-19 patients: A propensity score matched retrospective cohort study. Gastroenterology. 2020 May 22 doi: 10.1053/j.gastro.2020.05.053 [Epub ahead of print]

90) Deftereos SG, Giannopoulos G, Dimitrios A, et al. Effect of colchicine vs standard care on cardiac and inflammatory biomarkers and clinical outcomes in patients hospitalized with Coronavirus Disease 2019. The GRECCO-19 randomized clinical trial. JAMA Network Open. 2020;3:e2013136.

91) Rocco PRM, Silva PL, Cruz FF, et al. Early use of nitazoxanide in mild Covid-19 disease: randomized, placebo-controlled trial medRxiv 2020.10.21.20217208; doi: https://doi.org/10.1101/2020.10.21.20217208

92) Lenze EJ, Mattar C, Zorumski CF, et al. Fluvoxamine vs placebo and clinical deterioration in outpatients with symptomatic COVID-19. A randomized clinical trial. JAMA. Published online November 12, 2020. doi:10.1001/jama.2020.22760

93) Behera P, Patro BK, Singh AK, et al. Role of ivermectin in the prevention of COVID-19 infection among healthcare workers in India: A matched case-control study medRxiv 2020.10.29.20222661;

doi: https://doi.org/10.1101/2020.10.29.20222661 
94) Khan MSI,Khan MSI, Debnath CR, et al. Ivermectin treatment may improve the prognosis of patients with COVID-19. Archivos de Bronconeumología. 2020

95) Shouman W. https://ClinicalTrials.gov/show/NCT04422561 Results posted 27 Aug 20

96) Rajter JC, Sherman M, Fatteh N, et al. ICON (Ivermectin in COvid Nineteen) study: Use of ivermectin is associated with lower mortality in hospitalized patients with COVID19. medRxiv doi: https://doi.org/10.1101/2020.06.06.20124461

97) Shi L, Huang H, Lu X, et al. Treatment with human umbilical cord-derived mesenchymal stem cells for COVID-19 patients with lung damage: a randomised, double-blind, placebo-controlled phase 2 trial. medRxiv 2020.10.15.20213553; doi: https://doi.org/10.1101/2020.10.15.20213553

98) Folegatti PM, J Ewer KJ, Parvinder K Aley PK, et al. Safety and immunogenicity of the ChAdOx1 nCoV-19 vaccine against SARS-CoV-2: a preliminary report of a phase 1/2, single-blind, randomised controlled trial. Lancet. 2020 ;396(10249):467-478

99) Jackson LA, Anderson EJ, Rouphael NG, et al. An mRNA Vaccine against SARS-CoV-2 —preliminary report N Engl J Med. 2020 Jul 14;NEJMoa2022483. doi: 10.1056/NEJMoa2022483 
100) Zhu FC, Guan XH, Li YH, et al. Immunogenicity and safety of a recombinant adenovirus

type-5-vectored COVID-19 vaccine in healthy adults aged 18 years or older: a randomised, double-blind, placebo controlled, phase 2 trial. Lancet 2020; 395(10240):, P1845-1854, June 13, 2020

101) Keech C, Albert G, Cho I, et al. Phase 1-2 trial of a SARS-CoV-2 recombinant spike protein nanoparticle vaccine. New Engl J Med. DOI: 10.1056/NEJMoa2026920

102) Xia S, Duan K, Yuntao Zhang Y, et al. Effect of an inactivated vaccine against SARS-CoV-2 on safety and immunogenicity outcomes. Interim analysis of 2 randomized clinical trials. JAMA 2020 ;e2015543.doi: 10.1001/jama.2020.15543

103) Logunov DY, Dolzhikova IV, Zubkova OV, et al. Safety and immunogenicity of an rAd26 and rAd5 vector-based heterologous prime-boost COVID-19 vaccine in two formulations: two open, non-randomised phase 1/2 studies from Russia. Lancet. Published online September 4, 2020 https://doi.org/10.1016/S0140-6736(20)31866-31

104) Mulligan MJ, Lyke KE, Kitchin N, et al. Phase $1 / 2$ study to describe the safety and immunogenicity of a COVID-19 RNA vaccine candidate (BNT162b1) in adults 18 to 55 years of age: interim report. [published online ahead of print August 12, 2020] Nature 2020

105) Liu M, Thomadsen R, Yao S. Forecasting the spread of COVID-19 under different 
reopening strategies. Nature Scientific Reports (In Press)

106) Institute for Health Metrics and Evaluation. COVID-9 projections . Covid 19.healthdata.org

107) Marik PE, Varon J, Kory P. Treatment of Covid-19 is critically phase specific. Crit Care Shock 2020;23:10-12

108) Wan Y, Shang J, Sun S, et al. Molecular mechanism for antibody-dependent enhancement of coronavirus entry. J Virol 2020;94:e02015-19.

109) Fatima K, Syed NI. Dengvaxia controversy: impact on vaccine hesitancy. J Glob Health. 2018; 8(2): 020312.

110) Edridge AWD, Kaczorowska J, Hoste ACR et al. Coronavirus protective immunity is short-lasting.medRxiv preprint doi: https://doi.org/10.1101/2020.05.11.20086439.this version posted June 16, 2020.

111) Flu Vaccination Coverage, United States, 2019-20 Influenza Season. FluVaxView webpage report posted online October 1, 2020 https://www.cdc.gov/flu/fluvaxview/coverage-1920estimates.htm 
112) Zimmermann P, Nigel C. Coronavirus infections in children including COVID-19. An overview of the epidemiology, clinical features, diagnosis, treatment and prevention options in children.The Pediatric Infectious Disease Journal 2020;39 : 355-368

113) Sepkowitz KA. AIDS-The first 20 years. N Engl J Med 2001; 344 (23):1764-1772

114) Broder S. The development of antiretroviral therapy and its impact on the HIV-1/AIDS pandemic. Antiviral Res. 2010; 85(1): 1-18

115) Fauci AS. Preface: Evolving ethical issues over the course of the AIDS pandemic. Public Health Rev 34, 2 (2012)

116) Harris NS, Johnson AS, Huang YA, et al. Vital Signs: Status of human immunodeficiency virus testing, viral suppression, and HIV pre-exposure prophylaxis - United States, 2013-2018. MMWR Morb Mortal Wkly Rep. 2019; 68 (11):1117-1123 
TABLE 1. PUBLISHED STUDIES AS OF DECEMBER 27, 2020. Each agent is listed along with the country originating the publication. We have listed studies with 100 or more subjects. The type of control procedure: RCT: Randomized controlled study PLAC: Placebo, soc: standard of care which is variable depending on each location. AC: Active control: the control options are listed in parenthesis. OBS: retrospective observation study. LPV/R: lopanovir/ritonavir; HCQ: hydroxychloroquine; AZM: azithromycin; IFN: interferon; tocilizumab: TCZ. SEV: severe; CRIT: critical; MOD: moderate. W.H.O.: World Health Organization

\section{TREATMENT LOCATION TYPE OF NUMBER SETTING SEVERITY RESULTS \\ CONTROL SUBJECTS}

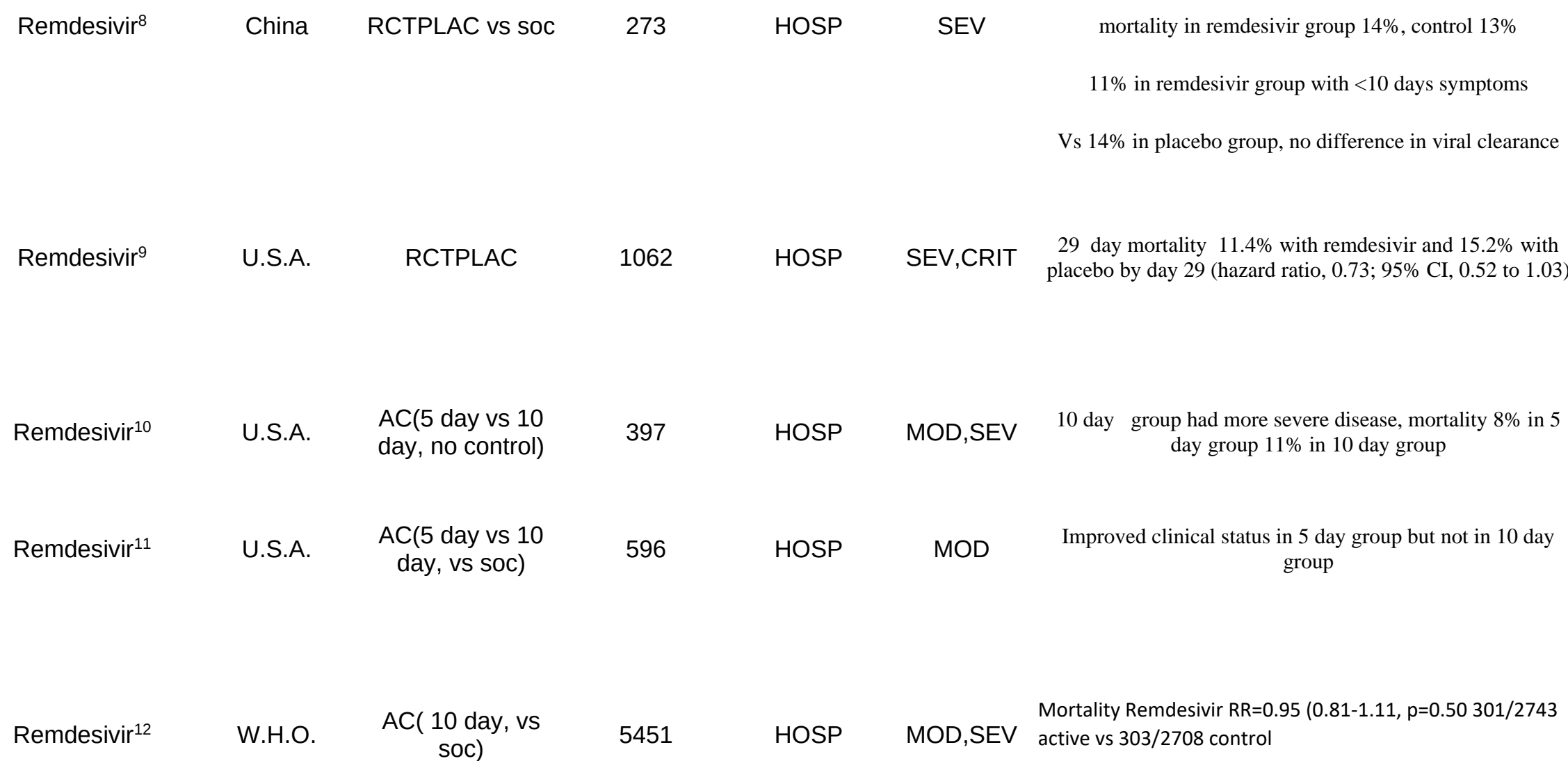


FVP $^{14}$

China
AC (umifenovir vs favipiravir)

Japan

OBS (no control)

1918

HOSP

MOD,SEV,C

RIT

MOD

By day 10 Clinical Improvement 27\% FVP vs 15\% soc , 98\%

HOSP

OBS(hcq+azm

$\mathrm{HCQ}^{19}$

France

noncomparable

control group)

3737

MIXED

MILD,MOD

$0.9 \%$ overall mortality, no sudden death, no cardiac arrythmias
$\mathrm{HCQ}^{22}$

$\mathrm{HCQ}^{23}$

$\mathrm{HCQ}^{24}$
China

RCT(hcq vs soc)

150
338

hcq)

OBS (hcq vs no
1376 hcq)

U.S.A.

U.S.A.
$\begin{gathered}\text { OBS(hcq vs no } \\ \text { hcq) }\end{gathered}$
U.S.A.
$\begin{gathered}\text { OBS (hcq vs no } \\ \text { hcq) }\end{gathered}$

HOSP

HOSP
HOSP MILD,MOD

No difference in viral clearance at 28 days

MOD,SEV Mortality twice as high in patients chosen for HCQ treatment

MOD,SEV

no significant association between HCQ use and intubation or death

(hazard ratio, 1.04, 95\% confidence interval, 0.82 to 1.32 ). 
$\mathrm{HCQ}^{25}$

U.S.A.

OBS (hcq+azt vs hcq vs azt)

France

OBS (hcq vs no

hcq)

OBS (hcq vs

$\mathrm{HCQ}^{27}$

U.S.A.

hcq plus azm,
azm

HOSP

MOD,SEV

\section{OBS (hcq vs}

$\mathrm{HCQ}^{28}$

U.S.A.

hcq plus azm,

azm

HOSP

RCT (hcq, -day unadjusted mortality for patients receiving

hydroxychloroquine alone, azithromycin alone, the combination or neither drug was $25 \%, 20 \%, 18 \%$, and $20 \%$,

HCQ treated patients were sicker with ppO2 223 vs 360 for controls

still lower than controls after propensity score matching 223 vs 273

Overall in-hospital mortality was $20.3 \%, 25.7 \%$ hcq+azt,

$$
19.9 \% \text { hcq alone }
$$

neither drug $17.7 \%$, cardiac arrest more likely with hcq+azt

no difference in mortality or need to transfer to ICU

Overall mortality was $18.1 \%(95 \%$

CI: $16.6 \%-19.7 \%)$; by treatment: hcq+azt, $(20.1 \%$ [95\% CI:

$17.3 \%-23.0 \%])$, hcq alone, (13.5\% [95\% CI: $11.6 \%-15.5 \%])$, azt alone,(22.4\% [95\% CI: $16.0 \%-30.1 \%])$, neither drug,

$$
(26.4 \%
$$

[95\% CI: $22.2 \%-31.0 \%])$. 
$\mathrm{HCQ}^{30}$

Brazil

RCT (azm vs soc)

RCT (Chloroquine

Chloroquine ${ }^{31}$

Brazil high dose to low dose)

121

HOSP

MOD,SEV

difference in viral clearance, higher mortality in high dose group azithromycin and control groups (OR 1.36 [95\% Cl 0.941.97], $p=0.11$ )
$\mathrm{HCQ}^{32}$

U.S.A.
RCT (HCQ vs $\mathrm{SOC})$

U.K.

RCT (HCQ vs

SOC)

1542

$\mathrm{HCQ}^{33}$

U.K.

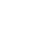

\section{$\mathrm{HCQ}^{12}$}

W.H.O.

$\mathrm{AC}(\mathrm{HCQ}$ vs soc)

1853

\section{OBS (hcq+azm}

$\mathrm{HCQ}^{34}$

U.S.A.

479
HOSP

HOSP

+azm)

U.S.A. RCTPLAC
821
HOSP

HOSP primary endpoint was not significantly different between the hydroxychloroquine vs. $25 \%$ usual care; hazard ratio 1.09 oc [95\% confidence interval 0.96-1.23]; $\mathrm{p}=0.18$ ) (Mortality $\mathrm{RR}=1.19(0.89-1.59, \mathrm{p}=0.23 ; 104 / 947$ HCQ vs $84 / 906$ control

Mortality RR=1.19 (0.89-1.59, $p=0.23 ; 104 / 947$ MOD, SEV HCQ vs $84 / 906$ control

MOD,SEV Reduction in mortality with addition of zinc OR $0.449,95 \% \mathrm{Cl}$ 0.271-0.744). 
$\mathrm{HCQ}^{36}$

U.S.A.

RCTPLAC

Spain

RCTPLAC

293

OUTPAT

MILD

$\mathrm{HCQ}^{37}$

Spain

RCTPLAC

OUTPAT

HEALTHY

no significant difference in the primary outcome of PCRconfirmed, symptomatic Covid-19 disease (6.2\% usual care 5.7\% HCQ; risk ratio 0.89 [95\% confidence interval 0.54

$1.46]$ ), nor evidence of prevention of SARS-CoV-2

transmission (17.8\% usual care vs. $18.7 \% \mathrm{HCQ})$

$\mathrm{HCQ}^{39}$

Portugal

OBS(HCQ vs no

HCQ)

OUTPAT

HEALTHY

odds ratio of SARS-CoV-2 infection for chronic treatment with HCQ $0.51(0.37-0.70)$.

2 month treatment with HCQ in hospital workers no significant difference in SARS-Cov-2 infection rate HCQ $6.3 \%$ vs placebo $6.6 \%$

3month treatment with HCQ in hospital workers no significant difference in SARS-Cov-2 infection rate HCQ 0.27 events per person/year vs placebo $0.38 \%(\mathrm{p}=0.18)$ 
$\mathrm{LPV} / \mathrm{r}^{44}$

U.K.

$\mathrm{RCT}(\mathrm{soc})$

W.H.O.

AC( LPV/r vs soc)

AC(Ipv/r+ribavirin

$\mathrm{LPV} / \mathrm{r}^{45}$

Hong Kong

+beta interferon

vs Ipv/r+ribavirin)

IFN- $\beta-1 a^{46}$

Cuba

OBS

$\mathrm{IFN}^{12}$

$\mathrm{AC}$ ( vs soc)

OBS

U.K.

$\mathrm{RCT}(\mathrm{soc})$

IFN- $\beta$ -

101

HOSP
2771

HOSP

1596

HOSP

127

761

HOSP

MIXED

MOD,SEV

Mortality LPV/r (RR=1.00

(0.79-1.25, $p=0.97 ; 148 / 1399$

vs $146 / 1372$

Mortality IFNRR=1.16 (0.96-1.39, $\mathrm{p}=0.11$;

4100

HOSP

MOD,SEV $243 / 2050$ vs $216 / 2050$ )

2944

OUTPAT

HEALTHY

No cases of COVID-19 compared to historical control $1 \mathrm{a}(\text { nebulized })^{51}$

MOD,SEV

OR for clinical improvement $2 \cdot 32(1 \cdot 07-5 \cdot 04)$ 


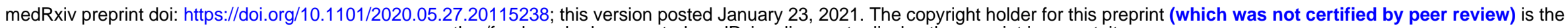

author/funder, who has granted medRxiv a license to display the preprint in perpetuity.
It is made available under a CC-BY-NC-ND 4.0 Interbasional license .

$\mathrm{TCZ}^{32}$

$\mathrm{TCZ}^{57}$

$\mathrm{TCZ}^{58}$

$\mathrm{TCZ}^{59}$

$\mathrm{TCZ}^{61}$

Italy

OBS

OBS

OBS (TCZ early

vs late treatment))

154

HOSP

CRIT

increased survival and avoidance mechanical ventilation with early treatment $95 \%$ CI 0.16 to $0.72, p=0.005$ ) and ICU admission or death (aHR 0.38, 95\% CI 0.19 to $0.81, \mathrm{p}=0.011$ ) among patients with baseline CRP $>150 \mathrm{mg} / \mathrm{L}$,

TCZ was associated with a $51 \%$ reduction in composite of death and mechanical ventilation $(\mathrm{HR})=0.49(95 \%$ confidence interval $(95 \mathrm{CI})=0.3-0.81), \mathrm{p}$-value $=0.005)$

$15.6 \%$ moratility at 14 days, $20 \%$ at 30 days in TCZ treated patients 


\section{Anakinra $^{66}$}

$\cdot$

$\mathrm{TCZ}^{68}$

6119

HOSP

MOD,SEV
$\mathrm{TCZ}^{69}$

Dexamethasone ${ }^{71}$

Brazil

$\mathrm{RCT}(\mathrm{soc})$

$\mathrm{RCT}(\mathrm{soc})$

U.K.

$\mathrm{SOC})$

Methylprednisolone ${ }^{7}$
TCZ treatment was associated with a reduced risk of invasive mechanical ventilation or death (adjusted hazard ratio $0 \cdot 61,95 \%$ CI $0 \cdot 40-0 \cdot 92 ; \mathrm{p}=0 \cdot 020$ ).

Incidence of severe respiratory failure $22 \%$ anakinra patients vs $59 \%$ soc, 30 day mortality $11.5 \%$ anakinra vs $22.3 \%$ soc ).

HR for mechanical ventilation or death at day 140.58 (90\% Crl, 0.30 to 1.09 ). day 28 mortality $11.1 \%$ TCZ, $11.9 \%$ soc (adjusted HR, 0.92 ; $95 \% \mathrm{Cl}$ 0.33-2.53).

Dexamethasone reduced 28-day

mortality by $35 \%$ in patients receiving invasive mechanical ventilation (rate ratio $0.65[95 \% \mathrm{Cl}$

0.51 to 0.82 ]; $p<0.001$ ) and by $20 \%$ in patients receiving oxygen without invasive mechanical ventilation (rate ratio 0.80 [95\% $\mathrm{Cl} 0.70$ to 0.92$] ; \mathrm{p}=0.002$

Mehtylprednisolone group had fewer deaths ( 6 vs. 21, adjusted $\mathrm{HR}=0.29 ; 95 \% \mathrm{Cl}: 0.12-0.73)$ and more days off invasive MV $(24.0$ plus-or-minus sign 9.0 vs. 17.5 plus-or-minus sign $12.8 ; p=0.001$ ) 
Methylprednisolone ${ }^{7}$ 4

Methylprednisolone ${ }^{7}$

Brazil

$\mathrm{RCT}(\mathrm{soc})$

HOSP

MOD,SEV

Overall 28 -day mortality was $76 / 199$ (38.2\%) in the placebo group vs $72 / 194(37.1 \%)$ in group which received methylprednisolone short 5 day course $(P=0.629)$

\section{Hydrocortisone ${ }^{79}$}

France

$\mathrm{RCT}(\mathrm{soc})$

149

HOSP

CRIT

$\mathrm{RCT}(\mathrm{soc})$

403

HOSP

SEV

$90 \%$ probability of superiority of hydrocortisone in organ support free days. No mortality difference

\section{Convalescent} plasma $^{81}$
China

$\mathrm{RCT}(\mathrm{soc})$

103

HOSP time to clinical improvement at 28 days was 4.9 days shorter (95\% CI, -9.33 to -0.54 days) in convalescent plasma group (HR, 2.15 [95\% CI, 1.07-4.32]; $\mathrm{P}=.03$ ). No significant difference in critically ill patients. Mortality 28-day mortality ( $15.7 \%$ convalescent plasma vs $24.0 \%$ control ; $\mathrm{P}=.30$ )

No significant difference mortality or rate hospital discharge
Early short course of methylprednisolone resulted in decrease need

$$
\mathrm{P}=.005)
$$


Convalescent plasma $^{85}$

U.S.A.

OBS

3,082

HOSP

MOD,SEV with plasma with low antibody levels (IgG) 35 or more days after COVID-19 diagnosis. By contrast 30-day mortality was $20 \%$ in 353 patients treated within 3 days

of diagnosis with plasma with high antibody levels.

Progression to severe disease or all cause mortality at 28 days after enrollment occurred in $44(19 \%)$ participants in

Convalescent plasma $^{87}$

India

$\mathrm{RCT}(\mathrm{soc})$

464

HOSP

MOD, SEV difference 0.008 ( $95 \%$ confidence interval -0.062 to 0.078 ) risk ratio $1.04,95 \%$ confidence interval 0.71 to 1.54 ).

LY-CoV555 88

U.S.A.

$\mathrm{RCT}(\mathrm{soc})$

OUTPAT

MILD,MOD

$6.2 \%$ of patients receiving placebo had emergency room visit or hospitalization vs $1.6 \%$ patients who received antibody

Famotidine $^{89}$

U.S.A.

OBS(famotidine vs

SOc)

HOSP

MOD,SEV

HR for famotidine for death or intubation $0.43,95 \% \mathrm{Cl}$ ( 0.21-0.88)
Art one week, $78 \%$ complete resolution symptoms in the nitazoxanide arm and $57 \%$ in the placebo arm ( $p=0.048)$. viral clearance in $29.9 \%$ of patients in the nitazoxanide arm versus $18.2 \%$ in the placebo arm $(p=0.009)$.) 


\section{Fluvoxamine $^{91}$}

Ivermectin $^{92}$

Ivermectin $^{93}$

India

Ivermectin $^{94}$

Bangladesh

Egypt

RCT( ivermectin vs

soc)

soc)

OBS(ivermectin vs

$$
\text { soc) }
$$

Case Control

Ivermectin vs

placebo)

Ivermectin $^{95}$

Mesenchymal

Stem Cells

China

RCTPLAC

101

HOSP

SEV

WITH LUNG

DAMAGE
Clinical deterioration in 0 patients on fluvoxamine, $8.7 \%$

placebo $(p<0.009)$

lower mortality in the ivermectin group (25.2\% versus $15.0 \%$,

OR $0.52,95 \% \mathrm{Cl} 0.29-0.96, \mathrm{P}=.03$ )

Two doses of ivermectin yielded 73\% reduction in COVID_9 cases

7.4\% developed COVID symptoms ivermectin vs $58.4 \% \%$ control

\section{Lesion volume decreased}

compared to placebo $(\mathrm{p}<0.05)$
ChAdOx1-nCoV1998

mRNA127399

Ad5 vectored

Covid Vaccine ${ }^{100}$
China

RCT(plac)
OUTPAT

HEALTHY

OUTPAT

HEALTHY

High neutralising antibody titiers, positive Th1-CD4 response

$$
\text { cell responses }
$$


NVX-Cov $2373^{10}$

Australia

RCT(plac)

China

RCT(plac)

OBS vectored Covid Vaccines ${ }^{103}$

BTN162b1 and b2 $2^{104}$

U.S.A.

$\mathrm{RCT}($ plac)
134

330

76

OUTPAT

HEALTHY

Significant neutralizing antibody titers and positive $T$ cell response
Significant neutralizing antibody titers and positive $T$ cell response

high titer, broad serum neutralizing responses, TH1

phenotype CD4+ Thelper cell responses, and strong interferon $\gamma$ (IFN $\gamma$ ) and interleukin-2 (IL-2) producing CD8+ cytotoxic T-cell responses 
(a)

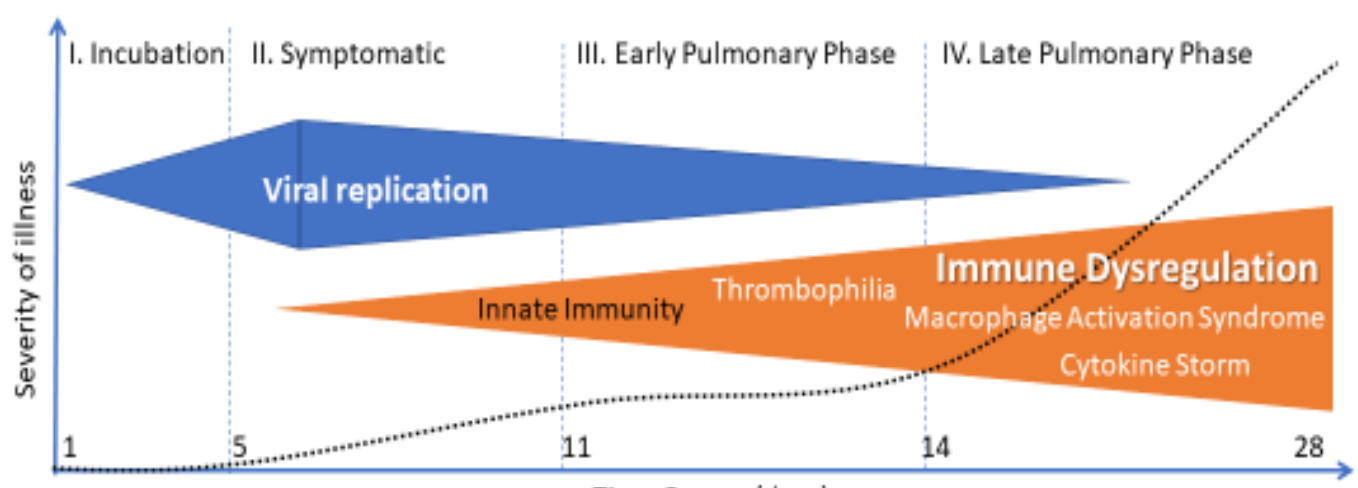

Time Course (days)

Ground-glass infiltrates

Clinical Symptoms

\begin{tabular}{|c|cc|}
\hline+1 & ++ \\
\hline $\begin{array}{l}\text { Fever, malaise, cough, } \\
\text { headache, diarrhea }\end{array}$ & $\begin{array}{l}\text { SOB }- \text { Mild hypoxia } \\
\leq 4 \mathrm{~L} / \text { min N/C \& aSat }<94 \%\end{array}$ & Progressive hypoxia \\
\hline
\end{tabular}

(b)

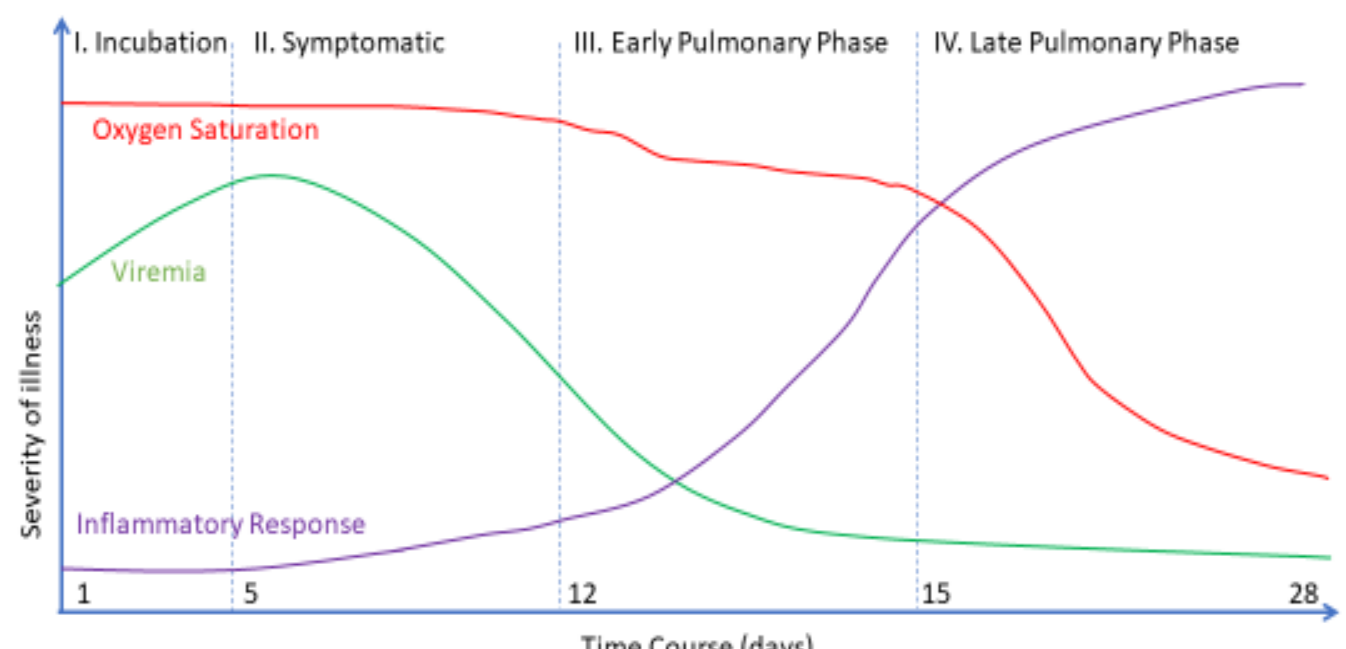

Figure 1: THE PHASES OF COVID-19 INFECTION. Asymptomatic viremia typically lasts for 5 days followed by symptoms of an upper respiratory infection. The immune response takes hold over the next week. Pneumonic infiltrates begin to appear. In patients destined for severe infection, a hyperinflammatory reaction takes hold, leading to worsening of pulmonary symptoms, hypoxia, and potentially acute respiratory distress syndrome. 


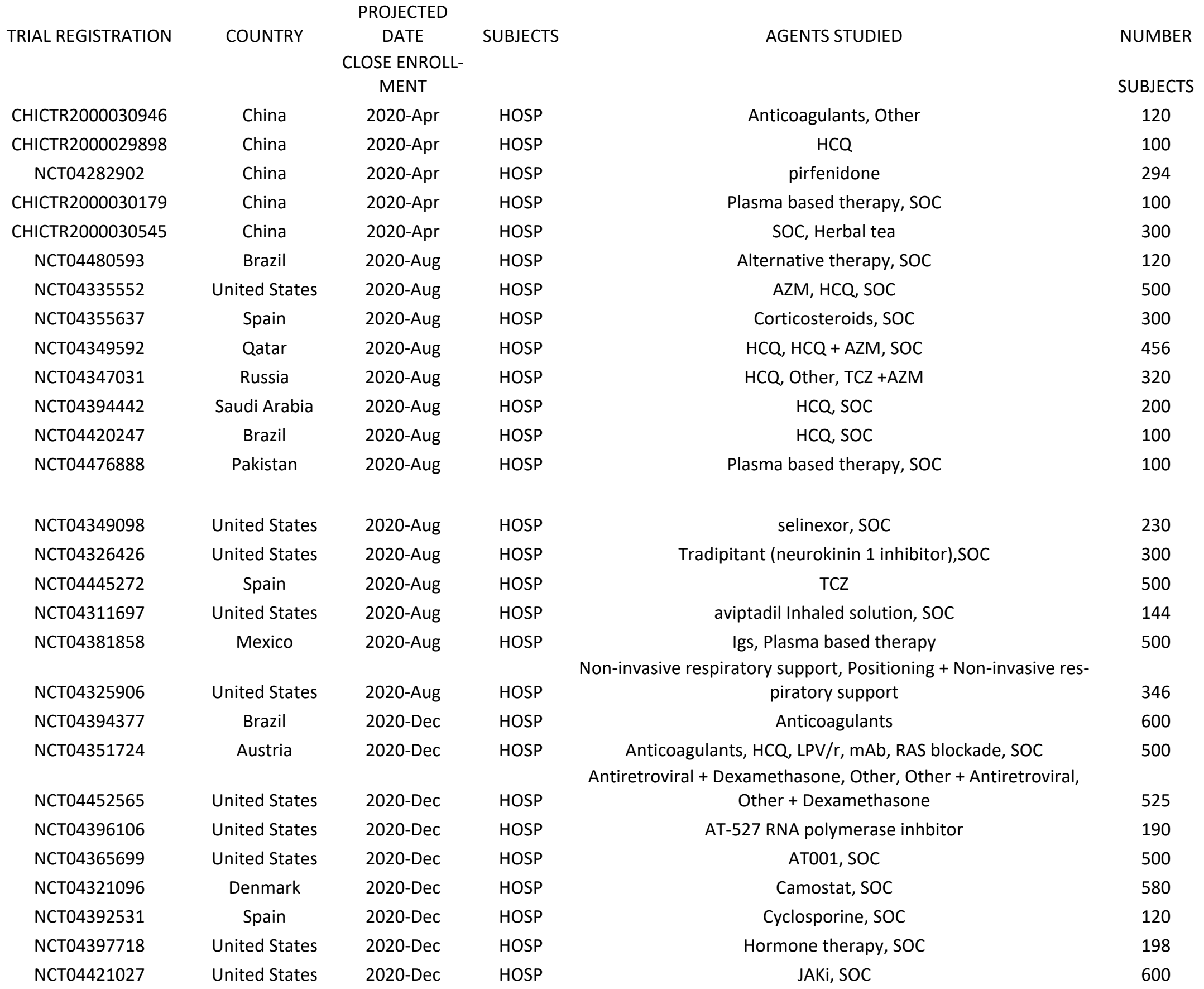


It is made available under a CC-BY-NC-ND 4.0 Interfodtional license.

\begin{tabular}{|c|c|c|c|}
\hline NCT04469114 & Israel & 2020-Dec & HOSP \\
\hline NCT04347239 & United States & 2020-Dec & HOSP \\
\hline NCT04376684 & United States & 2020-Dec & HOSP \\
\hline NCT04401202 & Saudi Arabia & 2020-Dec & HOSP \\
\hline NCT04432298 & United States & 2020-Dec & HOSP \\
\hline NCT04433546 & United States & 2020-Dec & HOSP \\
\hline NCT04392232 & United States & 2020-Dec & HOSP \\
\hline NCT04400058 & United States & 2020-Dec & HOSP \\
\hline NCT04359810 & United States & 2020-Dec & HOSP \\
\hline NCT04424797 & United States & 2020-Dec & HOSP \\
\hline NCT04391140 & Spain & 2020-Dec & HOSP \\
\hline NCT04402879 & Canada & 2020-Dec & HOSP \\
\hline NCT04365257 & United States & 2020-Dec & HOSP \\
\hline NCT04412356 & Sweden & 2020-Dec & HOSP \\
\hline NCT04479358 & United States & 2020-Dec & HOSP \\
\hline NCT04317092 & Italy & 2020-Dec & HOSP \\
\hline NCT04433910 & Germany & 2020-Dec & HOSP \\
\hline NCT04433910 & Germany & 2020-Dec & HOSP \\
\hline NCT04406389 & United States & 2020-Dec & HOSP \\
\hline NCT04344730 & France & 2020-Dec & HOSP \\
\hline NCT04480424 & United States & 2020-Dec & HOSP \\
\hline NCT04443881 & Spain & 2020-Dec & HOSP \\
\hline NCT04485429 & Brazil & 2020-Dec & HOSP \\
\hline NCT04466670 & Brazil & 2020-Dec & HOSP \\
\hline NCT04409509 & United States & 2020-Dec & HOSP \\
\hline NCT04535063 & Argentina & 2020-Dec & HOSP \\
\hline NCT04336462 & China & 2020-Feb & HOSP \\
\hline CHICTR2000032367 & China & 2020-Jul & HOSP \\
\hline NCT04355897 & United States & 2020-Jul & HOSP \\
\hline NCT04342182 & Netherlands & 2020-Jul & HOSP \\
\hline NCT04345523 & Spain & 2020-Jul & HOSP \\
\hline NCT04468646 & Pakistan & 2020-Jul & HOSP \\
\hline CHICTR2000030333 & China & 2020-Jul & HOSP \\
\hline NCT04459325 & Russia & 2020-Jul & HOSP \\
\hline NCT04322344 & Italy & 2020-Jun & HOSP \\
\hline
\end{tabular}

\begin{tabular}{|c|c|}
\hline JAKi, SOC & 260 \\
\hline Leronlimab, SOC & 390 \\
\hline $\mathrm{mAb}, \mathrm{SOC}$ & 800 \\
\hline Nigella sativa, SOC & 200 \\
\hline pamrevlumab (Ab to connective tisue growth factor), SOC & 130 \\
\hline pemziviptadil, SOC & 210 \\
\hline Plasma based therapy & 100 \\
\hline Plasma based therapy, SOC & 208 \\
\hline Plasma based therapy, SOC & 105 \\
\hline Positioning & 100 \\
\hline Positioning + Respiratory support, Respiratory support & 248 \\
\hline Positioning, SOC & 596 \\
\hline prazosin, SOC & 220 \\
\hline Procedure & 180 \\
\hline SOC, TCZ & 332 \\
\hline TCZ & 400 \\
\hline Plasma based therapy, SOC & 106 \\
\hline Plasma based therapy, SOC & 106 \\
\hline Anticoagulants & 186 \\
\hline Dexamethasone with or without respiratory suppport, SOC & 550 \\
\hline Ivlg, SOC & 100 \\
\hline Anakinra, SOC & 180 \\
\hline $\begin{array}{l}\text { Anticoagulants, Anticoagulants + Corticosteroids, Corticosteroids, } \\
\text { SOC }\end{array}$ & 268 \\
\hline Anticoagulants, Antihypertensive & 310 \\
\hline FX12 antbody, SOC & 124 \\
\hline Plasma based therapy & 200 \\
\hline Hydrogen, oxygen, SOC & 100 \\
\hline Exercise, SOC & 186 \\
\hline Plasma based therapy & 100 \\
\hline Plasma based therapy, SOC & 426 \\
\hline Plasma based therapy, SOC & 278 \\
\hline Neurokinin 1 receptor agonist, SOC & 100 \\
\hline pirfenidone, SOC & 292 \\
\hline dornase, alfa & 100 \\
\hline Alternative therapy, SOC & \\
\hline
\end{tabular}




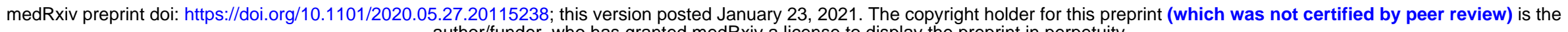
author/funder, who has granted medRxiv a license to display the preprint in perpetuity.

\begin{tabular}{|c|c|c|c|}
\hline NCT04305106 & China & 2020-Jun & HOSP \\
\hline NCT04375202 & Italy & 2020-Jun & HOSP \\
\hline NCT04347980 & France & 2020-Jun & HOSP \\
\hline CHICTR2000029777 & China & 2020-Jun & HOSP \\
\hline CHICTR2000029781 & China & 2020-Jun & HOSP \\
\hline CHICTR2000034796 & China & 2020-Mar & HOSP \\
\hline NCT04329195 & France & 2020-May & HOSP \\
\hline NCT04329650 & Spain & 2020-May & HOSP \\
\hline CHICTR2000030894 & China & 2020-May & HOSP \\
\hline CHICTR2000029603 & China & 2020-May & HOSP \\
\hline CHICTR2000030001 & China & 2020-May & HOSP \\
\hline CHICTR2000029763 & China & 2020-May & HOSP \\
\hline CHICTR2000029755 & China & 2020-May & HOSP \\
\hline CHICTR2000029765 & China & 2020-May & HOSP \\
\hline CHICTR2000030779 & China & 2020-May & HOSP \\
\hline NCT04310228 & China & 2020-May & HOSP \\
\hline NCT04346199 & Argentina & 2020-Nov & HOSP \\
\hline NCT04444700 & Brazil & 2020-Nov & HOSP \\
\hline NCT04362085 & Canada & 2020-Nov & HOSP \\
\hline NCT04344288 & France & 2020-Nov & HOSP \\
\hline NCT04382053 & Brazil & 2020-Nov & HOSP \\
\hline NCT04358081 & United States & 2020-Nov & HOSP \\
\hline NCT04362137 & United States & 2020-Nov & HOSP \\
\hline NCT04511819 & United States & 2020-Nov & HOSP \\
\hline NCT04448756 & United States & 2020-Nov & HOSP \\
\hline NCT04441385 & Spain & 2020-Nov & HOSP \\
\hline NCT04463420 & Iran & 2020-Nov & HOSP \\
\hline NCT04388410 & Mexico & 2020-Nov & HOSP \\
\hline NCT04495101 & Spain & 2020-Nov & HOSP \\
\hline NCT04449718 & Brazil & 2020-Nov & HOSP \\
\hline NCT04386850 & Iran & 2020-Nov & HOSP \\
\hline NCT04384900 & Denmark & 2020-Nov & HOSP \\
\hline NCT04400890 & United States & 2020-Nov & HOSP \\
\hline NCT04477655 & Mexico & 2020-Nov & HOSP \\
\hline NCT04427098 & Italy & $2020-O c t$ & HOSP \\
\hline NCT04530578 & Argentina & 2020-Oct & HOSP \\
\hline
\end{tabular}

Bevacizumab, SOC

140

Colchicine, SOC 308

Dexamethasone + $\mathrm{HCQ}, \mathrm{HCQ} \quad 122$

SOC, Herbal tea 160

SOC, Herbal tea $\quad 160$

Anticoagulants, SOC 160

Antihypertensive 554

Corticosteroids, Siltuximab 200

FPV, FPV + TCZ, TCZ

$\mathrm{LPV} / \mathrm{r}, \mathrm{ASC} 09 / \mathrm{r}$

LPV/r, Emcetrabine/r, SOC $\quad 240$

SOC, Heral Tea 408

SOC, Herbal tea $\quad 120$

SOC, TCZ 188

ulinastatin, SOC 100

FPV, FPV + TCZ, TCZ 150

Acalabrutinib, SOC 140

Anticoagulants, SOC 462

Anticoagulants, SOC 462

Corticosteroids, SOC 304

DFV890, SOC

$\mathrm{HCQ}, \mathrm{HCQ}+\mathrm{AZM}, \mathrm{SOC}$

JAKi, SOC 402

Losmapimod, SOC 410

M5049 (toll like receptor inhibitor), Other 150

Maraviroc, SOC 200

PHR160 asal spray+ HCQ + NSAIDs + AZM 224

Plasma based therapy, SOC 410

prolastin (proteinase inhibitor), SOC 100

SOC, Vitamin D 200

SOC, Vitamins $\quad 1500$

Positioning 150

Plant polyphenols 200

Positioning, SOC 200

Anticoagulants 300

Anticoagulants 200 


\begin{tabular}{|c|c|c|c|c|c|}
\hline NCT04486508 & Iran & $2020-$ Oct & HOSP & Anticoagulants, SOC, Statins & 600 \\
\hline NCT04470622 & United States & 2020-Oct & HOSP & Aprepitant (antiemetic), SOC & 100 \\
\hline NCT04340557 & United States & 2020-Oct & HOSP & ARB, SOC & 200 \\
\hline NCT04364893 & Brazil & 2020-Oct & HOSP & ARBs + ACEi, SOC & 700 \\
\hline NCT04350320 & Spain & 2020-Oct & HOSP & Colchicine, SOC & 102 \\
\hline NCT04322396 & Denmark & 2020-Oct & HOSP & $\mathrm{HCQ}+\mathrm{AZM}, \mathrm{SOC}$ & 226 \\
\hline NCT04348656 & United States & $2020-$ Oct & HOSP & Plasma based therapy, SOC & 1200 \\
\hline NCT04385043 & Italy & 2020-Oct & HOSP & Plasma based therapy, SOC & 400 \\
\hline NCT04395144 & Canada & 2020-Oct & HOSP & Positioning, SOC & 346 \\
\hline NCT04335071 & Switzerland & 2020-Oct & HOSP & SOC, TCZ & 100 \\
\hline NCT04385836 & Saudi Arabia & 2020-Sep & HOSP & alpha1 antitrypsin, SOC & 150 \\
\hline NCT04341116 & United States & 2020-Sep & HOSP & anti GM-CSF, SOC & 144 \\
\hline NCT04335136 & Austria & 2020-Sep & HOSP & Antihypertensive, SOC & 200 \\
\hline NCT04386616 & United States & 2020-Sep & HOSP & astegolimab, SOC & 300 \\
\hline NCT04452435 & India & 2020-Sep & HOSP & $\mathrm{C} 21, \mathrm{SOC}$ & 100 \\
\hline NCT04451174 & Chile & 2020-Sep & HOSP & Corticosteroids, SOC & 184 \\
\hline NCT04332094 & Spain & 2020-Sep & HOSP & $\mathrm{HCQ}+\mathrm{AZM}, \mathrm{TCZ}+\mathrm{AZM}+\mathrm{HCQ}$ & 276 \\
\hline NCT04403100 & Brazil & 2020-Sep & HOSP & $\mathrm{HCQ}, \mathrm{HCQ}+\mathrm{LPV} / \mathrm{r}, \mathrm{LPV} / \mathrm{r}, \mathrm{SOC}$ & 1968 \\
\hline NCT04370262 & United States & 2020-Sep & HOSP & $\mathrm{HCQ}, \mathrm{HCQ}+$ Other, SOC & 942 \\
\hline NCT04351152 & United States & 2020-Sep & HOSP & Lenzilumab, SOC & 300 \\
\hline NCT04334629 & United Kingdom & 2020-Sep & HOSP & NSAIDs, SOC & 230 \\
\hline NCT04374526 & Italy & 2020-Sep & HOSP & Plasma based therapy, SOC & 182 \\
\hline CHICTR2000030522 & China & 2020-Sep & HOSP & SOC, Herbal tea & 100 \\
\hline NCT04379271 & Bulgaria & 2020-Sep & HOSP & vidofludimus (pyrimidine synthesis inhibitor), SC & 230 \\
\hline NCT04377620 & United States & 2020-Sep & HOSP & JAKi, SOC & 500 \\
\hline NCT04445935 & Qatar & 2020-Sep & HOSP & Anticoagulants, SOC & 100 \\
\hline NCT04359277 & United States & 2021-Apr & HOSP & Anticoagulants & 1000 \\
\hline NCT04360824 & United States & 2021-Apr & HOSP & Anticoagulants & 170 \\
\hline NCT04360824 & United States & 2021-Apr & HOSP & Anticoagulants & 170 \\
\hline NCT04312009 & United States & 2021-Apr & HOSP & ARBs & 200 \\
\hline NCT04381377 & Russia & 2021-Apr & HOSP & Azoximer bromide, SOC & 394 \\
\hline NCT04367168 & Mexico & 2021-Apr & HOSP & Colchicine, SOC & 174 \\
\hline IRCT20200517047485N1 & Iran & 2021-Apr & HOSP & $\mathrm{HCQ}+$ Atazanavir/ritonavir, $\mathrm{HCQ}+\mathrm{LPV} / \mathrm{r}$ & 108 \\
\hline NCT04328493 & Vietnam & 2021-Apr & HOSP & $\mathrm{HCQ}, \mathrm{SOC}$ & 250 \\
\hline NCT04328493 & Vietnam & 2021-Apr & HOSP & $\mathrm{HCQ}, \mathrm{SOC}$ & 250 \\
\hline
\end{tabular}



author/funder, who has granted medRxiv a license to display the preprint in perpetuity.

\begin{tabular}{|c|c|c|c|c|c|}
\hline NCT04320056 & Canada & 2021-Apr & HOSP & Non-invasive respiratory support, SOC & 216 \\
\hline NCT04344431 & France & 2021-Apr & HOSP & Non-invasive respiratory support, SOC & 100 \\
\hline NCT04362176 & United States & 2021-Apr & HOSP & Plasma based therapy, SOC & 500 \\
\hline NCT04359797 & United States & 2021-Apr & HOSP & Positioning & 300 \\
\hline NCT04346615 & United States & 2021-Apr & HOSP & Zavegepant (CGRP agonist), SOC & 120 \\
\hline NCT04352751 & Pakistan & 2021-Apr & HOSP & Plasma based therapy & 2000 \\
\hline IRCT20200414047072N1 & Iran & 2021-Apr & HOSP & Plasma based therapy & 357 \\
\hline NCT04389710 & United States & 2021-Apr & HOSP & Plasma based therapy & 100 \\
\hline NCT04355143 & United States & 2021-Apr & HOSP & Colchicine, SOC & 150 \\
\hline NCT04387760 & Bahrain & 2021-Apr & HOSP & $\mathrm{FPV}, \mathrm{HCQ}, \mathrm{SOC}$ & 150 \\
\hline CHICTR2000029739 & China & 2021-Aug & HOSP & Non-invasive respiratory support & 440 \\
\hline NCT04513158 & United States & 2021-Aug & HOSP & Plasma based therapy & 100 \\
\hline NCT04345692 & United States & 2021-Dec & HOSP & $\mathrm{HCQ}, \mathrm{SOC}$ & 350 \\
\hline NCT04381936 & United Kingdom & 2021-Dec & HOSP & RECOVERY TRIAL Conv plasma vs TCZ vs Monoclonal Abs & 15000 \\
\hline CHICTR2000031430 & China & 2021-Dec & HOSP & SOC, Stem cells & 200 \\
\hline NCT04412772 & United States & 2021-Dec & HOSP & SOC, TCZ & 300 \\
\hline NCT04339816 & Czechia & 2021-Dec & HOSP & $\mathrm{HCQ}$ & 240 \\
\hline NCT04447469 & United States & 2021-Feb & HOSP & Antibody to GM-CSF & 573 \\
\hline NCT04390594 & Senegal & 2021-Feb & HOSP & $\mathrm{HCQ}, \mathrm{HCQ}+\mathrm{AZM}$ & 186 \\
\hline NCT04477993 & Brazil & 2021-Feb & HOSP & JAKi, SOC & 200 \\
\hline NCT04393246 & United Kingdom & 2021-Feb & HOSP & Other, SGLT2 + Other, SOC & 1407 \\
\hline CHICTR2000029757 & China & 2021-Feb & HOSP & Plasma based therapy, SOC & 200 \\
\hline NCT04348383 & Spain & 2021-Jan & HOSP & Antithrombotics, SOC & 120 \\
\hline NCT04338958 & Germany & 2021-Jan & HOSP & JAKi & 200 \\
\hline NCT04426695 & United States & 2021-Jan & HOSP & $\mathrm{mAB}$ & 2970 \\
\hline NCT04460183 & United Kingdom & 2021-Jan & HOSP & Non-invasive respiratory support, SOC & 300 \\
\hline CHICTR2000029806 & China & 2021-Jan & HOSP & PD1, thymosin, SOC & 120 \\
\hline NCT04439071 & United States & 2021-Jan & HOSP & PTC299 (DDODH inhibitor), SOC & 380 \\
\hline NCT04363814 & $\begin{array}{l}\text { Dominican Re- } \\
\text { public }\end{array}$ & 2021-Jul & HOSP & BAKTEC-R bacterial identification, SOC & 100 \\
\hline NCT04514627 & United States & 2021-Jul & HOSP & Other, SOC & 100 \\
\hline NCT04401423 & United States & 2021-Jun & HOSP & Antihypertensive, SOC & 100 \\
\hline NCT04359953 & France & 2021-Jun & HOSP & ARBs, AZM, HCQ & 1600 \\
\hline NCT04414631 & Switzerland & 2021-Jun & HOSP & Conestat alfa (C1esterase inhibitor), SOC & 120 \\
\hline NCT04345289 & Denmark & 2021-Jun & HOSP & Conv Plasma & 1100 \\
\hline NCT04432272 & United States & 2021-Jun & HOSP & Plasma based therapy & 500 \\
\hline
\end{tabular}




$\begin{array}{cccc}\text { NCT04418518 } & \text { United States } & \text { 2021-Jun } & \text { HOSP } \\ \text { NCT04364763 } & \text { United States } & \text { 2021-Jun } & \text { HOSP } \\ \text { NCT04322773 } & \text { Denmark } & \text { 2021-Jun } & \text { HOSP } \\ \text { NCT04323514 } & \text { Italy } & \text { 2021-Mar } & \text { HOSP } \\ \text { IRCT20170731035423N2 } & \text { Iran } & \text { 2021-Mar } & \text { HOSP } \\ \text { NCT04420299 } & \text { Spain } & \text { 2021-Mar } & \text { HOSP } \\ \text { NCT04351763 } & \text { Poland } & \text { 2021-Mar } & \text { HOSP } \\ \text { NCT04476979 } & \text { France } & \text { 2021-Mar } & \text { HOSP } \\ \text { NCT04373733 } & \text { United Kingdom } & \text { 2021-Mar } & \text { HOSP } \\ \text { NCT04342221 } & \text { Germany } & \text { 2021-Mar } & \text { HOSP } \\ \text { IRCT20170922036314N4 } & \text { Iran } & \text { 2021-Mar } & \text { HOSP } \\ \text { NCT04380961 } & \text { United States } & \text { 2021-Mar } & \text { HOSP } \\ \text { NCT04306393 } & \text { United States } & \text { 2021-Mar } & \text { HOSP } \\ \text { NCT04306393 } & \text { United States } & \text { 2021-Mar } & \text { HOSP } \\ \text { NCT04306393 } & \text { United States } & \text { 2021-Mar } & \text { HOSP } \\ \text { NCT04376034 } & \text { United States } & \text { 2021-Mar } & \text { HOSP } \\ \text { NCT04366050 } & \text { United States } & \text { 2021-May } & \text { HOSP } \\ \text { NCT04379492 } & \text { United States } & \text { 2021-May } & \text { HOSP } \\ \text { NCT04333420 } & \text { Netherlands } & \text { 2021-May } & \text { HOSP } \\ \text { NCT04390464 } & \text { United Kingdom } & \text { 2021-May } & \text { HOSP } \\ \text { NCT04365985 } & \text { United States } & \text { 2021-May } & \text { HOSP } \\ \text { NCT04516915 } & \text { United Kingdom } & \text { 2021-May } & \text { HOSP } \\ \text { IRCT20200501047258N1 } & \text { Iran } & \text { 2021-May } & \text { HOSP } \\ \text { NCT04374539 } & \text { Spain } & \text { 2021-May } & \text { HOSP } \\ \text { NCT04367077 } & \text { United States } & \text { 2021-Sep } & \text { HOSP } \\ \text { NCT04415086 } & \text { Brazil } & \text { 2022-Apr } & \text { HOSP } \\ \text { NCT04478071 } & \text { United States } & \text { 2022-Aug } & \text { HOSP } \\ \text { NCT04321993 } & \text { Canada } & \text { 2022-Feb } & \text { HOSP } \\ \text { NCT04394416 } & \text { United States } & \text { 2022-Jun } & \text { HOSP } \\ \text { NCT04330690 } & \text { Canada } & \text { 2022-Mar } & \text { HOSP } \\ \text { NCT04354831 } & \text { United States } & \text { 2022-May } & \text { HOSP } \\ \text { NCT04412486 } & \text { United States } & \text { 2022-May } & \text { HOSP } \\ \text { NCT04470544 } & \text { United States } & \text { 2022-Sep } & \text { HOSP } \\ \text { NCT04364737 } & \text { United States } & \text { 2023-Jan } & \text { HOSP } \\ \text { NCT04276896 } & \text { China } & \text { 2023-Jul } & \text { HOSP } \\ \text { NCT04415060 } & \text { Canada } & \text { 2023-Jun } & \text { HOSP }\end{array}$

Plasma-based therapy, soc

1200

RBT-9 (antiviral), SOC

Sarilumab, SOC, TCZ

$$
\text { Axcorbic Acid }
$$

BCC1 and Hep S, SOC

Bemiparin (low molecular wt heparin), SOC 120

$$
\text { CCB, Other, SOC }
$$

Corticosteroids, TCZ + Corticosteroids

$$
\mathrm{FPV}, \mathrm{HCQ}+\mathrm{AZM}+\text { Zinc, SOC } \quad 450
$$

$\mathrm{HCQ}, \mathrm{SOC}$

Psychological therapy, SOC $\quad 112$

sirukamab (IL6 inhibitor), SOC $\quad 270$

Non-invasive respiratory support, SOC 200

Non-invasive respiratory support, SOC 200

Non-invasive respiratory support, SOC 200

Plasma based therapy, SOC 240

$\begin{array}{ll}\text { ACEi, SOC } & 560 \\ \text { HCQ, SOC } & 120\end{array}$

IFN, SOC 390

JAKi, mAb, SOC $\quad 1167$

Opiate antagonists, Opiate antagonists + Anesthetic, SOC 500

Oseltamivir, vidoflidimus + Oseltamivir 120

Plasma based therapy, SOC 120

Plasma based therapy, SOC $\quad 116$

SOC, Stem cells $\quad 400$

Plasma-based therapy, SOC $\quad 120$

Vadadustat(hypoxia inducible factor), SOC 300

HCQ, JAKi, LPV/r, Sarilumab 800 Imatinib, SOC 204

LPV/r, SOC 2900

Plasma based therapy $\quad 131$

Plasma based therapy 100

Camostat, SOC 264

Plasma based therapy, SOC $\quad 300$

LV-SMENP-DC Vaccine 100

Anesthetic, SOC 752 


\begin{tabular}{|c|c|c|c|c|c|}
\hline NCT04315948 & Austria & 2023-Mar & HOSP & HCQ, LPV/r, LPV/r + IFN, Remdesivir, SOC & 3100 \\
\hline NCT04435353 & Kazakhstan & NA & HOSP & Alternative therapy & 200 \\
\hline CTRI/2020/05/025434 & India & NA & HOSP & Alternative therapy & 135 \\
\hline CTRI/2020/06/025977 & India & NA & HOSP & Alternative therapy, SOC & 120 \\
\hline CTRI/2020/06/025590 & India & NA & HOSP & Alternative therapy, SOC & 120 \\
\hline CTRI/2020/04/024883 & India & NA & HOSP & Alternative therapy, SOC & 112 \\
\hline NCT04347226 & United States & NA & HOSP & anti-IL8, SOC & 138 \\
\hline NCT04401293 & United States & NA & HOSP & Anticoagulants & 308 \\
\hline 2020-001972-13 & Italy & NA & HOSP & Anticoagulants & 300 \\
\hline NCT04508439 & Mexico & NA & HOSP & Anticoagulants & 130 \\
\hline NCT04372589 & United States & NA & HOSP & Anticoagulants, SOC & 3000 \\
\hline NCT04389840 & United States & NA & HOSP & Anticoagulants, SOC & 524 \\
\hline ACTRN12620000517976 & Australia & NA & HOSP & Anticoagulants, SOC & 206 \\
\hline NCT04493359 & Brazil & NA & HOSP & Antihypertensive & 240 \\
\hline NCT04328012 & United States & NA & HOSP & ARBs, $H C Q, L P V / r, S O C$ & 4000 \\
\hline ISRCTN48734830 & Sweden & NA & HOSP & ARBs, SOC & 750 \\
\hline NCT04335786 & Netherlands & NA & HOSP & ARBs, SOC & 651 \\
\hline CTRI/2020/05/025319 & India & NA & HOSP & ARBs, SOC & 186 \\
\hline CTRI/2020/05/025271 & India & NA & HOSP & BCG, SOC & 480 \\
\hline NCT04334460 & United States & NA & HOSP & BLD2660 (protese inhibitor), SOC & 120 \\
\hline CTRI/2020/06/026192 & India & NA & HOSP & $\mathrm{C} 21, \mathrm{SOC}$ & 100 \\
\hline NCT04362813 & United States & NA & HOSP & Canakinumab, SOC & 450 \\
\hline NCT04328480 & Argentina & NA & HOSP & Colchicine, SOC & 2500 \\
\hline NCT04381364 & Sweden & NA & HOSP & Corticosteroids, SOC & 446 \\
\hline NCT04331054 & France & NA & HOSP & Corticosteroids, SOC & 436 \\
\hline NCT04323592 & Italy & NA & HOSP & Corticosteroids, SOC & 104 \\
\hline NCT04345614 & United States & NA & HOSP & CRAC channel inhibitor, SOC & 400 \\
\hline NCT04395105 & Argentina & NA & HOSP & Dexamethasone, $\mathrm{SOC}$ & 284 \\
\hline NCT04424901 & United States & NA & HOSP & Dipyridamole, SOC & 100 \\
\hline 2020-001643-13 & United Kingdom & NA & HOSP & DPP1 inhibitor, SOC & 300 \\
\hline ISRCTN30564012 & United Kingdom & NA & HOSP & DPP1 inhibitor, SOC & 300 \\
\hline NCT04494984 & Argentina & NA & HOSP & Equine hyperimmune serum, SOC & 242 \\
\hline JPRN-JRCTS031190226 & Japan & NA & HOSP & FPV & 100 \\
\hline NCT04411433 & Turkey & NA & HOSP & $F P V, F P V+A Z M, H C Q, H C Q+A Z M, H C Q+F P V$ & 1000 \\
\hline CTRI/2020/06/025957 & India & NA & HOSP & FPV, FPV + Umifenovir & 158 \\
\hline 2020-001904-41 & United Kingdom & NA & HOSP & FPV, SOC & 302 \\
\hline
\end{tabular}




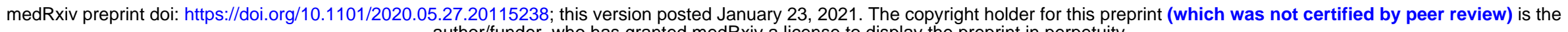
author/funder, who has granted medRxiv a license to display the preprint in perpetuity.

\begin{tabular}{|c|c|c|c|}
\hline CTRI/2020/06/025704 & India & NA & HOSP \\
\hline NCT04355052 & Israel & NA & HOSP \\
\hline NCT04392973 & Saudi Arabia & NA & HOSP \\
\hline NCT04346147 & Spain & NA & HOSP \\
\hline $2020-002035-30$ & Italy & NA & HOSP \\
\hline $2020-000936-23$ & Austria & NA & HOSP \\
\hline PACTR202004801273802 & Nigeria & NA & HOSP \\
\hline ISRCTN88057279 & United Kingdom & NA & HOSP \\
\hline NCT04459676 & Brazil & NA & HOSP \\
\hline NCT04382924 & United States & NA & HOSP \\
\hline 2020-001023-14 & United Kingdom & NA & HOSP \\
\hline NL8491 & Netherlands & NA & HOSP \\
\hline CTRI/2020/04/024806 & India & NA & HOSP \\
\hline $2020-001750-22$ & United Kingdom & NA & HOSP \\
\hline NCT04402866 & United Kingdom & NA & HOSP \\
\hline NCT04373044 & United States & NA & HOSP \\
\hline ISRCTN11188345 & United Kingdom & NA & HOSP \\
\hline NCT04404361 & United States & NA & HOSP \\
\hline 2020-001807-18 & Finland & NA & HOSP \\
\hline $2020-001759-42$ & Argentina & NA & HOSP \\
\hline NCT04382651 & United States & NA & HOSP \\
\hline NCT04374032 & $\begin{array}{c}\text { Bosnia \& Herze- } \\
\text { govina }\end{array}$ & NA & HOSP \\
\hline ISRCTN40580903 & United Kingdom & NA & HOSP \\
\hline $2020-001236-10$ & Netherlands & NA & HOSP \\
\hline NCT04395807 & Sweden & NA & HOSP \\
\hline NCT04467840 & Israel & NA & HOSP \\
\hline 2020-001805-21 & United Kingdom & NA & HOSP \\
\hline $2020-002229-27$ & United Kingdom & NA & HOSP \\
\hline ISRCTN60069084 & Oman & NA & HOSP \\
\hline NCT04472728 & United States & NA & HOSP \\
\hline NCT04408040 & United States & NA & HOSP \\
\hline NCT04393727 & Italy & NA & HOSP \\
\hline NCT04344535 & United States & NA & HOSP \\
\hline NCT04429854 & Belgium & NA & HOSP \\
\hline NL8633 & Netherlands & NA & HOSP \\
\hline
\end{tabular}

$\mathrm{HCQ}+\mathrm{FPV}, \mathrm{SOC} \quad 520$

$\mathrm{HCQ}+$ Imatinib, HCQ + JAKi, HCQ + LPV/r 165

$\mathrm{HCQ}, \mathrm{HCQ}+\mathrm{JAKi}$

$\mathrm{HCQ}, \mathrm{LPV} / \mathrm{r}$, Remdesivir 3100

$\mathrm{HCQ}, \mathrm{SOC} \quad 800$

$\mathrm{HCQ}, \mathrm{SOC}$

heptocyte growth factor, SOC 100

Ifenprodil, SOC 682

IFN, SOC 400

imatinib, SOC 386

Imatinib, SOC 100

Immunomodulators, JAKi, SOC 186

JAK1,SOC 159

JAKi, HCQ, SOC

JAKi, mAb, SOC 375

JAKi, SOC 358

JAKi, SOC 159

$\mathrm{mAb}, \mathrm{SOC} \quad 800$

MAS825, SOC

metenkefalin + tridecactide,SOC $\quad 120$

Mylotarg, Infliximab, Namilumab, SOC 588

NA 304

Non-invasive respiratory support 120

opaganib (sphingosine kinase), SOC 270

Oseltamivir, Oseltamivir + Other $\quad 120$

Other, Other + SGLT2, SOC 1407

Other, SOC 1180

Other, SOC 310

Plasma based therapy $\quad 700$

Plasma based therapy 126

Plasma based therapy, SOC $\quad 500$

Plasma based therapy, SOC 483

Plasma based therapy, SOC $\quad 430$ 


\begin{tabular}{|c|c|c|c|c|c|}
\hline NCT04479163 & Argentina & NA & HOSP & Plasma based therapy, SOC & 210 \\
\hline ISRCTN85216856 & Ecuador & NA & HOSP & Plasma based therapy, SOC & 200 \\
\hline NCT04358939 & France & NA & HOSP & Positioning & 248 \\
\hline NCT04366856 & France & NA & HOSP & Positioning, SOC & 500 \\
\hline NCT04383613 & Canada & NA & HOSP & Positioning, SOC & 350 \\
\hline ISRCTN54917435 & Sweden & NA & HOSP & Positioning, SOC & 240 \\
\hline NCT04343963 & Mexico & NA & HOSP & Pyridostigmine, SOC & 436 \\
\hline 2020-001497-30 & France & NA & HOSP & ravilizumab(complement inhibitor), SOC & 270 \\
\hline 2020-001786-36 & Belgium & NA & HOSP & Recombinant interleukin $7, \mathrm{SOC}$ & 200 \\
\hline 2020-001573-78 & United States & NA & HOSP & Recombinant interleukin $7, \mathrm{SOC}$ & 200 \\
\hline 2020-001453-49 & France & NA & HOSP & Remdesivir & 2500 \\
\hline NCT04409262 & United States & NA & HOSP & Remdesivir, Remdesivir + TCZ & 450 \\
\hline 2020-001052-18 & Denmark & NA & HOSP & Remdesivir, SOC & 440 \\
\hline ISRCTN13035264 & Denmark & NA & HOSP & Remdesivir, SOC & 400 \\
\hline NCT04359901 & United States & NA & HOSP & Sarilumab, SOC & 120 \\
\hline 2020-001473-79 & Italy & NA & HOSP & SGLT2, SOC & 900 \\
\hline NCT04389450 & United States & NA & HOSP & SOC, Stem cells & 140 \\
\hline CHICTR2000029990 & China & NA & HOSP & SOC, Stem cells & 120 \\
\hline NCT04366271 & Spain & NA & HOSP & SOC, Stem cells & 106 \\
\hline NCT04393415 & Egypt & NA & HOSP & SOC, Stem cells & 100 \\
\hline CTRI/2020/05/025369 & India & NA & HOSP & SOC, TCZ & 180 \\
\hline NCT04411446 & Argentina & NA & HOSP & SOC, Vitamins & 1265 \\
\hline ACTRN12620000454976 & Australia & NA & HOSP & SOC, Zinc & 160 \\
\hline 2020-002120-37 & France & NA & HOSP & sodium nitrite, $\mathrm{SOC}$ & 300 \\
\hline 2020-002060-31 & Czechia & NA & HOSP & SOLIDARITY TRIAL & 100000 \\
\hline ISRCTN83971151 & Argentina & NA & HOSP & SOLIDARITY TRIAL & 10000 \\
\hline CTRI/2020/04/024773 & Argentina & NA & HOSP & SOLIDARITY TRIAL & 7000 \\
\hline NCT04417257 & United States & NA & HOSP & tenretidine, SOC & 240 \\
\hline NCT04419623 & United States & NA & HOSP & TL-895 (tyrosine kinase inhibitor), SOC & 146 \\
\hline NL8504 & Netherlands & NA & HOSP & TCZ & 354 \\
\hline NCT04378920 & France & NA & HOSP & trancrocetin (NMDA inhibitor), SOC & 180 \\
\hline $2020-001264-28$ & Bulgaria & NA & HOSP & vidofludimus (pyrimidine synthesis inhibitor), SC & 200 \\
\hline NCT04453384 & France & NA & HOSP & XAV19( spike protein antibody), SOC & 368 \\
\hline NCT04373707 & France & NA & HOSP & Anticoagulants & 602 \\
\hline NCT04345848 & Switzerland & NA & HOSP & Anticoagulants & 200 \\
\hline CTRI/2020/06/026193 & India & NA & HOSP & $\mathrm{HCQ}+/-\mathrm{AZM}, \mathrm{HCQ}+$ Lithium +/- AZM & 100 \\
\hline
\end{tabular}




$\begin{array}{cccc}\text { NCT04321616 } & \text { Norway } & \text { NA } & \text { HOSP } \\ 2020-001754-21 & \text { France } & \text { NA } & \text { HOSP } \\ \text { NCT04346797 } & \text { France } & \text { NA } & \text { HOSP } \\ \text { NCT04347681 } & \text { Saudi Arabia } & \text { NA } & \text { HOSP } \\ \text { NCT04474340 } & \text { Kuwait } & \text { NA } & \text { HOSP } \\ \text { NCT04361253 } & \text { United States } & \text { NA } & \text { HOSP } \\ \text { NCT04401150 } & \text { Canada } & \text { NA } & \text { HOSP } \\ \text { NCT04498936 } & \text { Egypt } & \text { NA } & \text { HOSP } \\ \text { NCT04363853 } & \text { Mexico } & \text { NA } & \text { HOSP } \\ 2020-001644-25 & \text { Hrgentina } & \text { NA } & \text { HOSP } \\ \text { NCT04367831 } & \text { United States } & \text { NA } & \text { HOSP } \\ \text { NCT04409834 } & \text { United States } & \text { NA } & \text { HOSP } \\ 2020-001921-30 & \text { Italy } & \text { NA } & \text { HOSP } \\ \text { NCT04371367 } & \text { France } & \text { NA } & \text { HOSP } \\ \text { NCT04355364 } & \text { France } & \text { NA } & \text { HOSP } \\ \text { NCT04432051 } & \text { Turkey } & \text { NA } & \text { HOSP } \\ \text { NCT04358003 } & \text { United States } & \text { NA } & \text { HOSP } \\ \text { NCT04350580 } & \text { France } & \text { NA } & \text { HOSP } \\ \text { NCT04347941 } & \text { Ireland } & \text { NA } & \text { HOSP } \\ \text { JPRN-JRCT2031200126 } & \text { United States } & \text { NA } & \text { HOSP } \\ \text { NCT04371393 } & \text { United States } & \text { NA } & \text { HOSP } \\ \text { DRKS00021238 } & \text { Germany } & \text { NA } & \text { HOSP } \\ \text { NCT04264533 } & \text { China } & \text { NA } & \text { HOSP } \\ \text { NCT04364009 } & \text { France } & \text { NA } & \text { HOSP } \\ \text { JPRN-JRCTS031200026 } & \text { Japan } & \text { NA } & \text { HOSP } \\ \text { NACTR202007606032743 } & \text { Egypt } & \text { NA } & \text { HOSP } \\ \text { NCT04263402 } & \text { China } & \text { NA } & \text { HOSP } \\ \text { KCT0005105 } & \text { South Korea } & \text { NA } & \text { HOSP } \\ \text { NCT04361474 } & \text { France } & \text { NA } & \text { HOSP } \\ \text { NCT04530409 } & \text { Egypt } & \text { NA } & \text { HOSP } \\ \text { NCT04384588 } & \text { Chile } & \text { NA } & \text { HOSP } \\ \text { CTRI/2020/06/025803 } & \text { India } & \text { NA } & \text { HOSP } \\ \text { NCT04425915 } & \text { India } & \text { NA } & \text { HOSP } \\ \text { NCT04345419 } & \text { Egypt } & \text { NA } & \text { HOSP } \\ \text { Italy } & \text { NA } & \text { HOSP } \\ \text { N } & \text { NA States } & \text { OUTPAT }\end{array}$

$\mathrm{HCQ}$, Remdesivir, SOC

JAKi + TCZ or Anakinra, SOC, TCZ or Anakinra

$$
\mathrm{mAb}, \mathrm{sOC}
$$

Plasma based therapy

120

Plasma based therapy, SOC

575

Plasma based therapy, SOC

$$
\text { SOC, Vitamins }
$$

Sofosbuvir/Ledipasvir and Nitazoxanide, DAA, SOC

Acalabrutinib, SOC

Anticoagulants

100

Anticoagulants, Anticoagulants + Antiplatelets $\quad 750$

Anticoagulants, Corticosteroids + Anticoagulants 200

Avdirolimab (anti C5 antibody), SOC 108

dornase alfa, SOC 100

Monitoring, SOC 100

Plasma based therapy 2000

Polyvalent Immunoglbulin, SOC $\quad 138$

Positioning, SOC 200

ravilizumab (complement inhibitor), SOC 270

SOC, Stem cells 300

SOC, TCZ 200

SOC, Vitamin C 140

Anakinra, SOC 240

Anticoagulants, FPV 160

Anticoagulants, SOC $\quad 100$

Corticosteroids 100

Corticosteroids, HCQ + Corticosteroids, SOC 141

Corticosteroids, SOC 120

Dexamethasone 450

Plasma based therapy $\quad 100$

Plasma based therapy, SOC 400

Plasma based therapy, SOC 400

remdesivir, chloroquine, $\mathrm{SOC} \quad 120$

Sarilumab, SOC $\quad 171$

Alternative therapy, SOC $\quad 100$ 


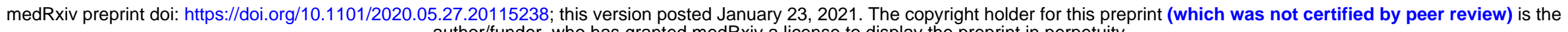
author/funder, who has granted medRxiv a license to display the preprint in perpetuity

\begin{tabular}{|c|c|c|c|c|c|}
\hline CHICTR2000029899 & China & 2020-Apr & OUTPAT & $\mathrm{HCQ}$ & 100 \\
\hline NCT04438850 & Italy & 2020-Aug & OUTPAT & Ivermectin, SOC & 102 \\
\hline NCT04337918 & Canada & 2020-Aug & OUTPAT & Non-invasive respiratory support & 200 \\
\hline NCT04369365 & Austria & 2020-Aug & OUTPAT & AZM, SOC & 200 \\
\hline CHICTR2000029601 & China & 2020-Aug & OUTPAT & Education, Education + Herbal tea & 400 \\
\hline NCT04466540 & Brazil & 2020-Aug & OUTPAT & $\mathrm{HCQ}, \mathrm{SOC}$ & 1300 \\
\hline NCT04466540 & Brazil & 2020-Aug & OUTPAT & $\mathrm{HCQ}, \mathrm{SOC}$ & 1300 \\
\hline NCT04438057 & United States & 2020-Aug & OUTPAT & Plasma based therapy, SOC & 150 \\
\hline NCT04406246 & Mexico & 2020-Dec & OUTPAT & Niazoxanide, SOC & 150 \\
\hline NCT04356495 & France & 2020-Dec & OUTPAT & Antihypertensive, FPV, HCQ, Other, SOC & 634 \\
\hline NCT04532931 & South Africa & 2020-Dec & OUTPAT & Antimalarial, DAA, FPV + Antivirals, SOC & 250 \\
\hline NCT04322682 & United States & 2020-Dec & OUTPAT & Colchicine, SOC & 6000 \\
\hline NCT04322565 & Italy & 2020-Dec & OUTPAT & Colchicine, SOC & 310 \\
\hline NCT04334382 & United States & 2020-Dec & OUTPAT & HCQ vs AZM & 1550 \\
\hline CHICTR2000029741 & China & 2020-Dec & OUTPAT & $\mathrm{HCQ}, \mathrm{LPV} / \mathrm{r}$ & 112 \\
\hline NCT04372628 & United States & 2020-Dec & OUTPAT & $\mathrm{HCQ}, \mathrm{LPV} / \mathrm{r}, \mathrm{SOC}$ & 600 \\
\hline NCT04529525 & Argentina & 2020-Dec & OUTPAT & Ivermectin, SOC & 500 \\
\hline NCT04446377 & United States & 2020-Dec & OUTPAT & LAM002 (lysosome activator), SOC & 142 \\
\hline NCT04425629 & United States & 2020-Dec & OUTPAT & $\mathrm{mAB}, \mathrm{SOC}$ & 2104 \\
\hline NCT04342728 & United States & 2020-Dec & OUTPAT & SOC, Ascorbic Acid, Ascorbic Acid + Zinc, Zinc & 520 \\
\hline CHICTR2000029621 & China & 2020-Dec & OUTPAT & SOC, Umifenovir & 380 \\
\hline NCT04338074 & United States & 2020-Dec & OUTPAT & tranexamic acid & 100 \\
\hline NCT04464408 & Saudi Arabia & 2020-Dec & OUTPAT & FPV, SOC & 576 \\
\hline CHICTR2000029780 & China & 2020-Jun & OUTPAT & SOC, Herbal tea & 160 \\
\hline NCT04346667 & Pakistan & 2020-May & OUTPAT & $\mathrm{HCQ}, \mathrm{SOC}$ & 400 \\
\hline NCT04351191 & Pakistan & 2020-May & OUTPAT & $\mathrm{HCQ}, \mathrm{SOC}$ & 400 \\
\hline NCT04345991 & France & 2020-May & OUTPAT & Plasma based therapy, SOC & 120 \\
\hline NCT04416399 & United Kingdom & 2020-Nov & OUTPAT & Corticosteroids, SOC & 478 \\
\hline NCT04517422 & Mexico & 2020-Nov & OUTPAT & Nutrition, SOC & 300 \\
\hline NCT04486313 & United States & 2020-Oct & OUTPAT & Antivirals + Vitamins, Vitamins & 800 \\
\hline NCT04363827 & Italy & 2020-Sep & OUTPAT & $\mathrm{HCQ}, \mathrm{SOC}$ & 2300 \\
\hline NCT04332107 & United States & 2020-Sep & OUTPAT & AZM, SOC & 2271 \\
\hline NCT04381962 & United Kingdom & 2020-Sep & OUTPAT & AZM, SOC & 800 \\
\hline NCT04416334 & Spain & 2020-Sep & OUTPAT & Colchicine, SOC & 1028 \\
\hline NCT04377711 & United States & 2020-Sep & OUTPAT & Corticosteroids, SOC & 400 \\
\hline NCT04370782 & United States & 2020-Sep & OUTPAT & $\mathrm{HCQ}+\mathrm{AZM}+$ Zinc, $\mathrm{HCQ}+$ Zinc + Antibiotics & 750 \\
\hline
\end{tabular}




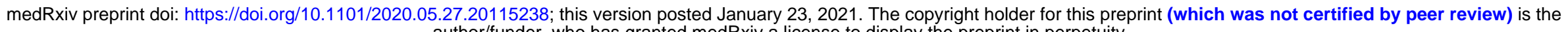
author/funder, who has granted medRxiv a license to display the preprint in perpetuity.

\begin{tabular}{|c|c|c|c|c|c|}
\hline NCT04331600 & Poland & 2020-Sep & OUTPAT & $\mathrm{HCQ}, \mathrm{SOC}$ & 400 \\
\hline NCT04518410 & United States & 2020-Sep & OUTPAT & Other, SOC & 2000 \\
\hline CHICTR2000033057 & China & 2020-Sep & OUTPAT & Rehabilitation & 160 \\
\hline NCT04427501 & United States & 2020-Sep & OUTPAT & $\mathrm{mAB}, \mathrm{SOC}$ & 800 \\
\hline NCT04329923 & United States & 2021-Apr & OUTPAT & $\mathrm{HCQ}, \mathrm{SOC}$ & 400 \\
\hline NCT04390503 & United States & 2021-Apr & OUTPAT & Plasma based therapy, SOC & 200 \\
\hline NCT04311177 & United States & 2021-Apr & OUTPAT & ARBs, SOC & 580 \\
\hline NCT04523090 & South Africa & 2021-Apr & OUTPAT & Nitozoxanide & 960 \\
\hline CHICTR2000029589 & China & 2021-Dec & OUTPAT & SOC, Herbal tea & 120 \\
\hline CHICTR2000029539 & China & 2021-Feb & OUTPAT & $\mathrm{LPV} / \mathrm{r}, \mathrm{SOC}$ & 328 \\
\hline NCT04460690 & United States & 2021-Jul & OUTPAT & Rapid SARS-Cov-2 detection & 5000 \\
\hline NCT04475601 & Sweden & 2021-Jul & OUTPAT & Hormone therapy, SOC & 500 \\
\hline NCT04342689 & United States & 2021-Jun & OUTPAT & Nutrition, SOC & 1500 \\
\hline NCT04418505 & United States & 2021-Mar & OUTPAT & Alternative therapy, SOC & 280 \\
\hline NCT04357990 & Iceland & 2021-Mar & OUTPAT & Alternative therapy, SOC & 128 \\
\hline NCT04400799 & Switzerland & 2021-Mar & OUTPAT & Anticoagulants, SOC & 1000 \\
\hline CHICTR2000030804 & China & 2021-Mar & OUTPAT & SOC, Herbal tea & 128 \\
\hline NCT04353284 & United States & 2021-May & OUTPAT & Camostat, SOC & 114 \\
\hline NCT04331899 & United States & 2021-May & OUTPAT & IFN, SOC & 120 \\
\hline NCT04342169 & United States & 2022-Apr & OUTPAT & $\mathrm{HCQ}, \mathrm{SOC}$ & 400 \\
\hline NCT04373460 & United States & 2022-Dec & OUTPAT & Plasma based therapy, SOC & 1344 \\
\hline NCT04355767 & United States & 2022-Dec & OUTPAT & Plasma based therapy, SOC & 600 \\
\hline CHICTR2000030084 & China & 2022-Feb & OUTPAT & Psychological therapy, SOC & 180 \\
\hline CTRI/2020/05/025490 & India & NA & OUTPAT & Alternative therapy, SOC & 110 \\
\hline NCT04404218 & Canada & NA & OUTPAT & Acai Berry, SOC & 480 \\
\hline ISRCTN13311119 & India & NA & OUTPAT & Alternative therapy, SOC & 116 \\
\hline JPRN-UMIN000040602 & Brazil & NA & OUTPAT & Alternative therapy, SOC & 100 \\
\hline ISRCTN59048638 & Mexico & NA & OUTPAT & Anticoagulants, SOC & 200 \\
\hline NCT04365582 & France & NA & OUTPAT & AZM, HCQ, LPV/r, SOC & 640 \\
\hline NCT04359329 & United States & NA & OUTPAT & Estrogen steroid hormone, SOC & 110 \\
\hline $2020-002106-68$ & United Kingdom & NA & OUTPAT & $F P V, L P V / r, L P V / r+F P V, S O C$ & 240 \\
\hline NCT04346628 & United States & NA & OUTPAT & FPV, SOC & 120 \\
\hline ISRCTN86534580 & United Kingdom & NA & OUTPAT & $\mathrm{HCQ}, \mathrm{SOC}$ & 3000 \\
\hline 2020-001469-35 & Poland & NA & OUTPAT & $\mathrm{HCQ}, \mathrm{SOC}$ & 400 \\
\hline NCT04351516 & Germany & NA & OUTPAT & $\mathrm{HCQ}, \mathrm{SOC}$ & 350 \\
\hline $2020-001558-23$ & Italy & NA & OUTPAT & $\mathrm{HCQ}, \mathrm{SOC}$ & 216 \\
\hline
\end{tabular}




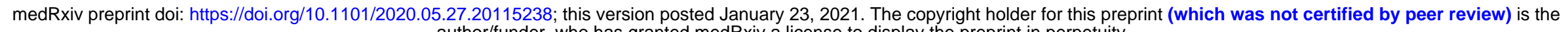
author/funder, who has granted medRxiv a license to display the preprint in perpetuity.
It is made available under a CC-BY-NC-ND 4.0 Internazional license .

\begin{tabular}{|c|c|c|c|c|c|}
\hline CHICTR2000029867 & China & 2021-Feb & $\begin{array}{c}\text { OUTPAT, } \\
\text { HOSP }\end{array}$ & Carrimycin, LPV/r & 520 \\
\hline NCT04394117 & Australia & 2021-Jan & $\begin{array}{c}\text { OUTPAT, } \\
\text { HOSP }\end{array}$ & ARBs, SOC & 605 \\
\hline NCT04419025 & United States & 2021-Jan & $\begin{array}{c}\text { OUTPAT, } \\
\text { HOSP }\end{array}$ & $\mathrm{N}$-acetyl ccysteine & 200 \\
\hline NCT04500418 & Germany & 2021-Sep & $\begin{array}{c}\text { OUTPAT, } \\
\text { HOSP }\end{array}$ & cenicriviroc (CCR2 and CCR5 receptor blocker), SOC & 183 \\
\hline CTRI/2020/06/025763 & India & NA & $\begin{array}{c}\text { OUTPAT, } \\
\text { HOSP }\end{array}$ & Alternative therapy & 150 \\
\hline ISRCTN14212905 & United Kingdom & NA & $\begin{array}{c}\text { OUTPAT, } \\
\text { HOSP }\end{array}$ & Anticoagulants, Other, SOC & 100 \\
\hline 2020-001498-63 & Belgium & NA & $\begin{array}{c}\text { OUTPAT, } \\
\text { HOSP }\end{array}$ & BIO101 (MAS activator) & 465 \\
\hline CHICTR2000029573 & China & NA & $\begin{array}{c}\text { OUTPAT, } \\
\text { HOSP } \\
\text { OUTPAT }\end{array}$ & cytokine derived gene protein, $\mathrm{SOC}$ & 480 \\
\hline NCT04445467 & Australia & NA & HOSP & FPV, SOC & 190 \\
\hline NCT04336332 & United States & NA & $\begin{array}{c}\text { OUTPAT, } \\
\text { HOSP }\end{array}$ & $\mathrm{HCQ}, \mathrm{HCQ}+\mathrm{AZM}, \mathrm{SOC}$ & 160 \\
\hline NCT04385095 & United Kingdom & NA & $\begin{array}{c}\text { OUTPAT, } \\
\text { HOSP }\end{array}$ & IFN, SOC & 820 \\
\hline ISRCTN14241621 & United Kingdom & NA & $\begin{array}{c}\text { OUTPAT, } \\
\text { HOSP } \\
\text { OUTPAT, }\end{array}$ & IFN, SOC & 220 \\
\hline NCT04354259 & Canada & NA & HOSP & IFN, SOC & 140 \\
\hline 2020-001860-27 & United Kingdom & NA & $\begin{array}{l}\text { OUTPAT, } \\
\text { HOSP }\end{array}$ & multiple drugs, SOC & 250 \\
\hline NCT04377308 & United States & NA & $\begin{array}{c}\text { OUTPAT, } \\
\text { HOSP }\end{array}$ & SOC, SSRIs & 2000 \\
\hline $2020-001501-24$ & Italy & NA & PREV & $\mathrm{HCQ}, \mathrm{SOC}$ & 2300 \\
\hline NCT04374942 & Canada & 2020-Aug & PREV & $\mathrm{HCQ}, \mathrm{SOC}$ & 988 \\
\hline NCT04359537 & Pakistan & 2020-Aug & PREV & $\mathrm{HCQ}, \mathrm{SOC}$ & 200 \\
\hline CHICTR2000029602 & China & 2020-Aug & PREV & Education + Monitoring + Herbal tea, Psychological therapy & 600 \\
\hline NCT04380701 & Germany & 2020-Aug & PREV & BNT162 RNA Vaccine & 200 \\
\hline NCT04334928 & Spain & 2020-Dec & PREV & $\mathrm{HCQ}, \mathrm{HCQ}+\mathrm{NRTIS}, \mathrm{NRTIS}, \mathrm{SOC}$ & 4000 \\
\hline NCT04318015 & Mexico & 2020-Dec & PREV & $\mathrm{HCQ}, \mathrm{SOC}$ & 400 \\
\hline NCT04348435 & United States & 2020-Dec & PREV & SOC, Stem cells & 100 \\
\hline CHICTR2000031944 & China & 2020-Dec & PREV & SOC, Herbal Tea & 2000 \\
\hline NCT04530357 & Kazakhstan & 2020-Dec & PREV & QAZ-Covid Inactivated Vaccine, SOC & 244 \\
\hline
\end{tabular}




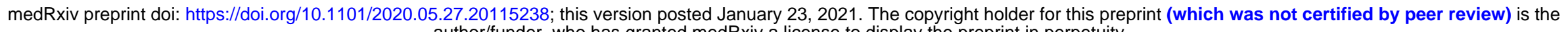
author/funder, who has granted medRxiv a license to display the preprint in perpetuity

\begin{tabular}{|c|c|c|c|}
\hline NCT04369794 & Brazil & NA & PREV \\
\hline NCT04470427 & United States & NA & PREV \\
\hline CTRI/2020/06/025769 & India & NA & PREV \\
\hline CTRI/2020/05/025484 & India & NA & PREV \\
\hline CTRI/2020/05/025491 & India & NA & PREV \\
\hline CTRI/2020/07/026560 & India & NA & PREV \\
\hline IRCT20130306012728N8 & Iran & NA & PREV \\
\hline NCT04387409 & Germany & NA & PREV \\
\hline NCT04384549 & France & NA & PREV \\
\hline NCT04381988 & United States & NA & PREV \\
\hline $2020-002287-31$ & Spain & NA & PREV \\
\hline ISRCTN17072692 & United Kingdom & NA & PREV \\
\hline NCT04357028 & Egypt & NA & PREV \\
\hline NCT04445389 & South Korea & NA & PREV \\
\hline NCT04470609 & China & NA & PREV \\
\hline NCT04439045 & Canada & NA & PREV \\
\hline NCT04445428 & Guinea-Bissau & NA & PREV \\
\hline ISRCTN89951424 & Brazil & NA & PREV \\
\hline NL8547 & Netherlands & NA & PREV \\
\hline NCT04442048 & Canada & NA & PREV \\
\hline ISRCTN15281137 & United Kingdom & NA & PREV \\
\hline CTRI/2020/07/026352 & India & NA & PREV \\
\hline NCT04436276 & United States & NA & PREV \\
\hline NCT04412538 & China & NA & PREV \\
\hline RPCEC00000314 & Cuba & NA & PREV \\
\hline ISRCTN90906759 & United Kingdom & NA & PREV \\
\hline CTRI/2020/06/025861 & India & NA & PREV \\
\hline NCT04498442 & United States & NA & PREV \\
\hline CHICTR2000030937 & China & 2020-Aug & TAIL \\
\hline CHICTR2000030720 & China & 2020-Aug & TAIL \\
\hline NCT04368845 & Greece & 2020-Jul & TAIL \\
\hline CHICTR2000030987 & China & 2020-Jun & TAIL \\
\hline NCT04333589 & China & 2020-Jun & TAIL \\
\hline NCT04394169 & Spain & 2020-Sep & TAIL \\
\hline CHICTR2000029789 & China & 2021-Jun & TAIL \\
\hline CHICTR2000030920 & China & 2021-May & TAIL \\
\hline
\end{tabular}

SOC, Vaccine

1000

SOC, Vaccine mRNA1273 30000

Alternative therapy, SOC 40000

Alternative therapy, SOC $\quad 5000$

Alternative therapy, SOC $\quad 1000$

Alternative therapy, SOC 200

$\begin{array}{cc}\text { HCQ, SOC } & 500 \\ \text { SOC, Vaccine } & 1200 \\ \text { SOC, Vaccine } & 1120\end{array}$

$\mathrm{HCQ}+$ Radiation therapy, Radiation therapy 132 HCQ, SOC 1930

LNP-nCoVsaRNA Vaccine $\quad 320$

measles vaccine, $\mathrm{SOC} \quad 200$

SOC, GX-19 DNA Vaccine 210

SOC, SARS-Cov-2 inactivated vaccine 471

SOC, Vaccine $\quad 3626$

SOC, Vaccine 3400

SOC, Vaccine 2000

SOC, Vaccine $\quad 1600$

SOC, Vaccine $\quad 1500$

SOC, Vaccine 1112

SOC, Vaccine 1048

SOC, Vaccine 1045

SOC, Vaccine 942

SOC, Vaccine Finlay Vaccine Institute $\quad 115000$

Vaccine 12330

Alternative therapy, SOC $\quad 500$

Exercise, Other, Respiratory support 30000

SOC, Herbal tea $\quad 144$

SOC, Herbal tea $\quad 120$

Non-invasive respiratory support, SOC $\quad 100$

FPV, FPV + HCQ, SOC $\quad 150$

FPV, SOC 210

Rehabilitation, SOC 102

SOC, Herbal tea $\quad 100$

SOC, Herbal tea $\quad 100$ 


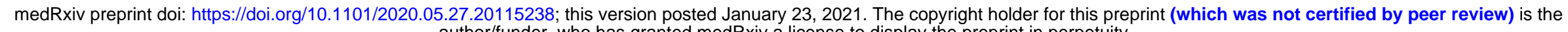
author/funder, who has granted medRxiv a license to display the preprint in perpetuity.

\begin{tabular}{|c|c|c|c|c|c|}
\hline CHICTR2000029790 & China & $2020-$-Oct & UNCLEAR & SOC, Herbal tea & 120 \\
\hline NCT04353336 & Egypt & 2020-Sep & UNCLEAR & $\mathrm{HCQ}$ & 200 \\
\hline NCT04325893 & France & 2020-Sep & UNCLEAR & $\mathrm{HCQ}, \mathrm{SOC}$ & 1300 \\
\hline NCT04429711 & Israel & 2020-Sep & UNCLEAR & Ivermectin, SOC & 100 \\
\hline NCT04463264 & Argentina & 2020-Sep & UNCLEAR & Nitazoxanide, SOC & 135 \\
\hline NCT04338698 & Pakistan & 2020-Sep & UNCLEAR & Oseltamavir vs Azithromycin vs $\mathrm{HCQ}$ & 500 \\
\hline NCT04449588 & China & 2021-Aug & UNCLEAR & BDB001 (toll like receptor agonist), SOC & 368 \\
\hline CHICTR2000030117 & China & 2021-Dec & UNCLEAR & LPV/r + IFN, Herbal tea & 348 \\
\hline CHICTR2000029935 & China & 2021-Feb & UNCLEAR & $\mathrm{HCQ}$ & 100 \\
\hline CHICTR2000029939 & China & 2021-Feb & UNCLEAR & $\mathrm{HCQ}, \mathrm{SOC}$ & 100 \\
\hline NCT04421508 & United States & 2021-Feb & UNCLEAR & Non-invasive respiratory support, SOC & 500 \\
\hline CHICTR2000029605 & China & 2021-Feb & UNCLEAR & SOC, Herbal tea & 400 \\
\hline CHICTR2000029747 & China & 2021-Feb & UNCLEAR & SOC, Herbal tea & 200 \\
\hline RCT20110726007117N11 & Iran & 2021-Jan & UNCLEAR & SOC, Vitamin D & 210 \\
\hline NCT04334512 & United States & 2021-Jun & UNCLEAR & HCQ,AZM, Vitamins, Zinc & 600 \\
\hline NCT04344041 & France & 2021-May & UNCLEAR & ,Vitamin D, SOC & 260 \\
\hline CHICTR2000032919 & China & 2021-May & UNCLEAR & SOC, Herbal tea & 200 \\
\hline NCT04395768 & Australia & 2021-Sep & UNCLEAR & $\mathrm{HCQ}+\mathrm{AZM}+$ Zinc + Vitamins & 200 \\
\hline CHICTR2000029756 & China & 2022-Feb & UNCLEAR & IFN, Herbal tea & 238 \\
\hline CHICTR2000029976 & China & 2022-Feb & UNCLEAR & Psychological therapy, SOC & 160 \\
\hline CTRI/2020/06/026221 & India & NA & UNCLEAR & Alternative therapy, $\mathrm{HCQ}$ & 100 \\
\hline CTRI/2020/06/025557 & India & NA & UNCLEAR & Alternative therapy, SOC & 420 \\
\hline CTRI/2020/07/026468 & India & NA & UNCLEAR & Alternative therapy, SOC & 140 \\
\hline NСT04351347 & Egypt & NA & UNCLEAR & Antivirals, $\mathrm{HCQ}$, Ivermectin & 300 \\
\hline CHICTR2000032769 & China & NA & UNCLEAR & Azuvidine, SOC & 342 \\
\hline NCT04471766 & Guinea-Bissau & NA & UNCLEAR & Cloth face mask, SOC & 66000 \\
\hline CTRI/2020/05/025320 & India & NA & UNCLEAR & Exercise + Nutrition + Hygiene + Alternative therapy + Other, SOC & 658 \\
\hline CTRI/2020/06/025575 & India & NA & UNCLEAR & $\mathrm{HCQ}+$ ribavirin, $\mathrm{LPV} / \mathrm{r}+$ ribavirin & 175 \\
\hline NCT04374019 & United States & NA & UNCLEAR & $\mathrm{HCQ}, \mathrm{HCQ}+\mathrm{AZM}, \mathrm{HCQ}+$ Ivermectin, Other & 240 \\
\hline NCT04447534 & Egypt & NA & UNCLEAR & $\mathrm{HCQ}, \mathrm{HCQ}+$ Zinc & 200 \\
\hline NCT04403555 & Egypt & NA & UNCLEAR & $\mathrm{HCQ}$, Ivermectin + Docycline & 200 \\
\hline NCT04410562 & Spain & NA & UNCLEAR & $\mathrm{HCQ}, \mathrm{SOC}$ & 714 \\
\hline NCT04352959 & France & NA & UNCLEAR & Hygiene, SOC & 178 \\
\hline RPCEC00000307 & Cuba & NA & UNCLEAR & IFN & 120 \\
\hline CHICTR2000029638 & China & NA & UNCLEAR & IFN & 100 \\
\hline CHICTR2000030262 & China & NA & UNCLEAR & IFN, SOC & 140 \\
\hline
\end{tabular}




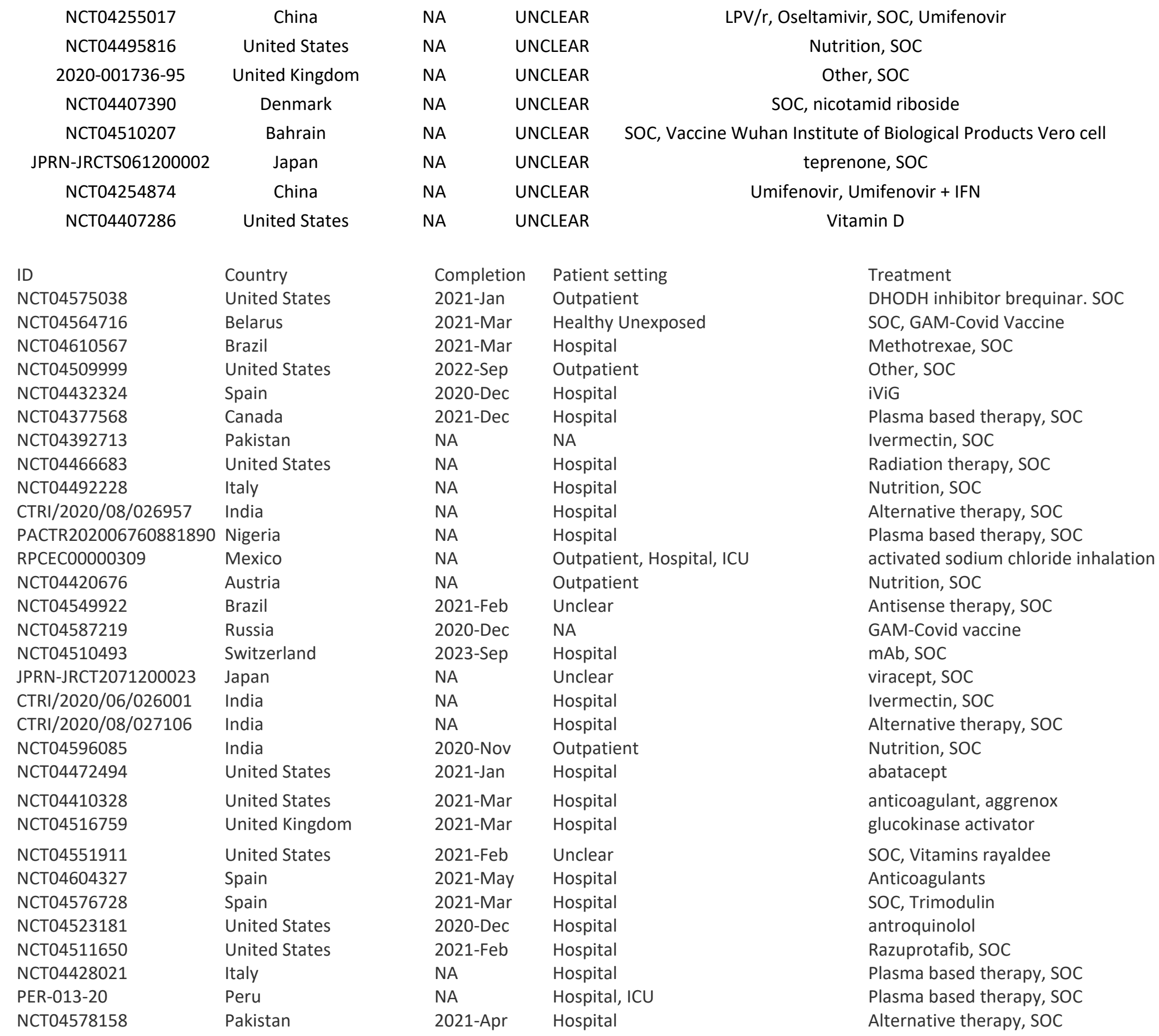

400

126

45000

100

100

DHODH inhibitor brequinar. SOC

iViG

Ivermectin, SOC

Nutrition, SOC

Nutrition, $\mathrm{SOC}$

$\mathrm{mAb}, \mathrm{SOC}$

pt, SOC

Alternative therapy, SOC

Nutrition, SOC

anticoagulant, aggrenox

glucokinase activato

Anticoagulants

Razuprotafib, SOC

Alternative therapy 


\begin{tabular}{|c|c|c|c|c|}
\hline NCT04583956 & United States & 2021-Jan & Hospital & Remdesivir, Remdesivir + mAb \\
\hline NCT04558021 & Turkey & 2021-Jan & NA & Niclosamide \\
\hline $2020-001329-30$ & China & NA & ICU & Non-invasive respiratory support \\
\hline ACTRN12620000557932 & Australia & NA & Hospital & $\mathrm{HCQ}+$ Zinc + Vitamins + AZT \\
\hline CTRI/2020/06/025768 & India & NA & Unclear & Alternative therapy \\
\hline NCT04622865 & France & 2021-Jun & Hospital & Alternative therapy + Other, $\mathrm{HCQ}$ \\
\hline NCT04357457 & France & NA & Hospital & Respiratory stimulant, SOC \\
\hline NCT04499677 & United Kingdom & NA & Outpatient & FPV, LPV/r, LPV/r + FPV, SOC \\
\hline NCT04523246 & United States & 2021-Jul & Nursing home residents & SOC, shingrix Vaccine \\
\hline NCT04568031 & Japan & 2021-Sep & NA & Vaccine ChAdOx1 Vector Vaccine (nn-replicating) \\
\hline NCT04498247 & United States & 2022-Apr & NA & V591 Merck Vaccine \\
\hline NCT04583592 & United States & 2020-Dec & Outpatient & Camostat, SOC \\
\hline $2020-002713-17$ & Mexico & NA & Hospital & Immunomodulators, mAb, SOC \\
\hline NCT04370236 & United States & 2021-Feb & Hospital & INBO3, checkpoint inhibitor \\
\hline NCT04455815 & United Kingdom & 2021-Aug & Outpatient & Camostat, SOC \\
\hline NCT04530435 & Denmark & 2021-Apr & Outpatient & Respiratory support, SOC \\
\hline NCT04535674 & Spain & NA & Hospital & Other, SOC \\
\hline $2020-001662-11$ & France & NA & Hospital & JAKi, SOC \\
\hline NCT04603924 & United States & 2021-Jun & Hospital & Other, SOC Niclosamide \\
\hline NCT04494646 & United States & 2021-Jan & Hospital & SOC, Triterpenes \\
\hline NCT04435795 & Canada & 2021-Feb & Outpatient & Corticosteroids, SOC \\
\hline NCT04581954 & United Kingdom & 2021-Jun & Hospital & Immunomodulators, JAKi, SOC \\
\hline NCT04377750 & Israel & 2020-Apr & ICU & SOC, TCZ \\
\hline NCT04321096 & Denmark & 2020-Dec & Hospital & Other, SOC \\
\hline NCT04504032 & United States & 2020-Dec & Outpatient & Anticoagulants, SOC \\
\hline CHICTR2000039000 & China & 2020-Dec & NA & SOC, Inactivated SARS Cov 2 vaccine \\
\hline NCT04335084 & United States & 2021-Jun & Healthcare Workers & $\mathrm{HCQ}+$ Vitamins + Zinc, SOC \\
\hline NCT04471636 & Germany & NA & Outpatient & Device + Other, SOC \\
\hline NCT04589949 & Netherlands & 2022-Nov & Outpatient & Plasma-based therapy \\
\hline NCT04376684 & United States & 2020-Dec & Hospital & $\mathrm{mAb}, \mathrm{SOC}$ \\
\hline CTRI/2020/07/026791 & India & NA & Hospital & Antihypertensive, SOC, Statins \\
\hline NCT04350593 & United States & 2020-Oct & Hospital & SGLT2, SOC \\
\hline NCT04504734 & United States & 2021-Feb & Outpatient & Antirheumatic, SOC bucillamine \\
\hline ACTRN12620000473965 & Australia & NA & Healthcare Workers & Immunomodulators, SOC \\
\hline NCT04492475 & United States & 2023-Nov & Hospital & Remdesivir, Remdesivir + IFN \\
\hline 2020-001072-15 & United Kingdom & NA & Healthy Unexposed & Vaccine \\
\hline NCT04359095 & Colombia & 2020-Nov & Hospital & $\mathrm{AZT}, \mathrm{HCQ}, \mathrm{LPV} / \mathrm{r}, \mathrm{SOC}$ \\
\hline NCT04501952 & United States & 2020-Dec & Outpatient & Remdesivir, SOC \\
\hline NCT04575584 & United States & 2021-Apr & NA & Antivirals molnupiravir, SOC \\
\hline NCT04545060 & United States & 2021-Jan & Outpatient & Monoclonal antibody, SOC \\
\hline NCT04606563 & United States & 2021-Jun & NA & ARBs, SOC \\
\hline NCT04575597 & United States & 2021-Apr & Outpatient & Antivirals, SOC \\
\hline CTRI/2020/08/027170 & India & NA & Healthy Unexposed & SOC, Vaccine Covishield \\
\hline NCT04444674 & South Africa & 2020-Oct & NA & SOC, Vaccine ChAdOx1 nCoV-19) \\
\hline
\end{tabular}



author/funder, who has granted medRxiv a license to display the preprint in perpetuity. It is made available under a CC-BY-NC-ND 4.0 Interolional license. 


\begin{tabular}{|c|c|c|c|c|c|}
\hline IRCT20200525047562N1 & Iran & 2020-Jul & HOSP & Plasma based therapy, SOC & 100 \\
\hline IRCT20080901001165N58 & Iran & 2020-Jun & HOSP & Plasma based therapy, SOC & 100 \\
\hline IRCT20190727044343N2 & Iran & 2020-Apr & HOSP & SOC, Statins & 100 \\
\hline NCT04288102 & China & 2020-May & HOSP & SOC, Stem cells & 100 \\
\hline NCT04363736 & United States & 2020-Aug & HOSP & TCZ & 100 \\
\hline IRCT20120225009124N4 & Iran & 2020-Jun & HOSP & $\begin{array}{c}\text { Corticosteroids + Igs + IFN, } \\
\text { HCQ + Antivirals }\end{array}$ & 105 \\
\hline IRCT20200402046923N1 & Iran & 2020-May & HOSP & Alternative therapy, SOC & 110 \\
\hline IRCT20200415047092N1 & Iran & 2020-May & HOSP & $\begin{array}{c}\text { AZT + Oseltamivir + LPV/r + } \\
\text { Antiretroviral + HCQ } \\
\text { Oseltamivir + LPV/r + } \\
\text { Antiretroviral + HCQ }\end{array}$ & 110 \\
\hline IRCT20200411047025N1 & Iran & 2020-May & HOSP & $\begin{array}{c}\mathrm{HCQ}+\text { Antiretroviral, } \mathrm{HCQ}+ \\
\text { Antiretroviral + Vitamins }\end{array}$ & 110 \\
\hline IRCT20171122037571N2 & Iran & 2020-May & HOSP & $\begin{array}{c}\text { Remdesivir + Chloroqines + } \\
\text { LPV/r or Atazanavir }\end{array}$ & 120 \\
\hline IRCT20200405046951N1 & Iran & 2020-Aug & HOSP & SOC, Vitamin A & 120 \\
\hline NCT04276688 & China & 2020-Mar & HOSP & $L P V / r, L P V / r+I F N$ & 127 \\
\hline NCT04473170 & $\begin{array}{l}\text { United Arab } \\
\text { Emirates }\end{array}$ & 2020-May & HOSP & SOC, Stem cells & 146 \\
\hline IRCT20200316046792N1 & Iran & 2020-May & HOSP & Alternative therapy, SOC & 150 \\
\hline IRCT20200411047016N1 & Iran & 2020-Jun & HOSP & Alternative therapy, SOC & 150 \\
\hline IRCT20200705048013N1 & Iran & 2020-Jul & HOSP & HCQ + Vitamins + Non- & 150 \\
\hline
\end{tabular}




CHICTR2000029308
IRCT20200325046860N1
IRCT20160310026998N11
IRCT20080901001165N46
CHICTR2000030254
NCT04323527
IRCT20200318046812N1
IRCT20160316027081N1
NCT04327388
NCT04321278
NCT04320615
NCT04332991
IRCT20200624047908N1
NCT04280705
NCT04292899
IRCT20200510047383N1
IRCT20200508047345N1
IRCT20200415047089N1
NCT04349241
IRCT20160313027033N2
NCT04483830
NCT04365738
NCT04337541

CHICTR2000029308 RCT20200325046860N1 IRCT20160310026998N11 RCT20080901001165N46

$\begin{array}{cc}\text { China } & \text { 2021-Jan } \\ \text { Iran } & \text { 2020-Aug } \\ \text { Iran } & \text { 2020-Apr } \\ \text { Iran } & \text { 2020-Aug } \\ \text { China } & \text { NA } \\ \text { Brazil } & \text { 2020-May } \\ \text { Iran } & \text { 2020-Jun } \\ \text { Iran } & \text { 2020-Apr } \\ \text { Argentina } & \text { 2020-Jul } \\ \text { Brazil } & \text { 2020-Jun }\end{array}$

HOSP
HOSP
HOSP
HOSP
HOSP
HOSP
HOSP
HOSP
HOSP
HOSP

United States

2020-Jun

United States

2020-Jun

Iran

United States

2020-Sep

2020-May

2020-Apr

2020-Aug

2020-Jun

Iran

Iran

Egypt

Iran

Mexico

Turkey

2020-Apr

$\begin{array}{ll}\text { Spain } & \text { 2020-Jun } \\ \text { Iran } & \text { 2020-Apr } \\ \text { Denmark } & \text { 2020-Jun }\end{array}$

OUTPAT

OUTPAT

PREV invasive respiratory support +

Plasma based therapy, Other

\begin{tabular}{|c|c|}
\hline LPV/r, SOC & 160 \\
\hline Conv plasma, SOC & 200 \\
\hline metformin, SOC & 200 \\
\hline SOC, Umifenovir & 200 \\
\hline FPV, Umifenovir & 240 \\
\hline $\mathrm{HCQ}$ & 278 \\
\hline $\mathrm{HCQ}+\mathrm{FPV}, \mathrm{HCQ}+\mathrm{LPV} / \mathrm{r}$ & 324 \\
\hline licorice, SOC & 374 \\
\hline Sarilumab, SOC & 421 \\
\hline $\mathrm{HCQ}, \mathrm{HCQ}+\mathrm{AZT}$ & 440 \\
\hline SOC, TCZ & 450 \\
\hline HCQ, SOC & 479 \\
\hline DAA, SOC & 1000 \\
\hline Remdesivir, SOC & 1062 \\
\hline Remdesivir & 4891 \\
\hline SOC, TCZ & 100 \\
\hline Alternative therapy & 100 \\
\hline Alternative therapy, SOC & 100 \\
\hline FPV, SOC & 100 \\
\hline Nutrition, SOC & 120 \\
\hline Anticoagulants, SOC & 243 \\
\hline $\begin{array}{l}\text { Education, Non-invasive } \\
\text { respiratory support }\end{array}$ & 270 \\
\hline HCQ + Antivirals, SOC & 2300 \\
\hline Noscapine, SOC & 125 \\
\hline Surgical Face mask, SOC & 6000 \\
\hline
\end{tabular}


